\title{
The Effects of Lesions of Telencephalic Visual Structures on Visual Discriminative Performance in Turtles (Chrysemys picta picta)
}

\author{
ANTON REINER AND ALICE SCHADE POWERS \\ Department of Anatomy and Cell Biology, University of Michigan, Ann Arbor, \\ Michigan 48109 (A.R.) and Department of Psychology, Bryn Mawr College, Bryn Mawr, \\ Pennsylvania 19010 (A.S.P.)
}

\begin{abstract}
Ascending thalamotelencephalic visual pathways that terminate in specific telencephalic regions have been described in all reptiles studied. Although the anatomical data suggests that such telencephalic regions may play a role in visual processing in reptiles, few behavioral data are available. In the present study, the effects of destruction of either the core nucleus (CN) of the dorsal ventricular ridge (telencephalic terminus of the tectothalamofugal pathway) or the dorsal cortex (telencephalic terminus of the retinothalamofugal pathway) on visual discriminative performance in the turtle were examined. Following extensive bilateral destruction of the $\mathrm{CN}$, turtles were severely impaired in their performance of both a simultaneous pattern discrimination and a simultaneous visual intensity discrimination. The extent of the discriminative impairment was found to be specifically correlated with the amount of $\mathrm{CN}$ damage. In contrast to the effects of CN lesions, lesions of the dorsal cortex had no evident effect on the performance of either a simultaneous pattern discrimination or a simultaneous visual intensity discrimination. The present results suggest that, as in birds and mammals, telencephalic visual areas play an important role in visual functions in reptiles. As in at least some birds (such as pigeons), the telencephalic terminus of the tectothalamofugal visual pathway appears to play a larger, or at least more readily measurable, role in visual discrimination than does the telencephalic terminus of the retinothalamofugal pathway.
\end{abstract}

Key words: core nucleus, dorsal cortex, turtles, visual function, lesions, discrimination

\begin{abstract}
Anatomical, physiological, and behavioral investigations have demonstrated the existence of visual lemniscal pathways to the telencephalon in birds and mammals. Although the existence and functions of the visual pathway to the striate cortex in mammals have long been recognized, the existence and functions of visual pathways to extrastriate cortical regions in mammals have only recently become apparent (Harting et al., '72, '73; Snyder, '73; Hughes, '77; Sprague et al., '77). Studies of the avian central visual pathways have elucidated the anatomical organization and functions of two visual lemniscal pathways to the avian telencephalon (Hodos and Karten, '66, '70; Hunt and Webster, '72; Hodos et al., '73; Karten et al., '73; Hodos and Bonbright, '74; Pettigrew and Konishi, '76; Pasternak and Hodos, '77). These two visual pathways in birds have been termed the thalamofugal and tectofugal ${ }^{1}$ visual pathways and have been suggested to be comparable to
\end{abstract}

the mammalian visual pathways to the striate and extrastriate cortices, respectively (Karten, '69; Nauta and Karten, '70; Karten, "79).

In reptiles, two distinct visual pathways, a retinothalamofugal and tectothalamofugal (see footnote 1), also terminate within separate circumscribed telencephalic regions (Hall and Ebner, 70a,b; Pritz, 75; Hall et al., '77; Lohman and van Woerden-Verkley, '78; Balaban and Ulin-

'The convention of referring to these two pathways as the thalamofugal and tectofugal is widespread, particularly in the avian literature. Since, however, both pathways relay in the thalamus, both are actually thalamofugal pathways. To differentiate these pathways more precisely, we shall refer to them as the retinothalamofugal and tectothalarnofugal, respectively.

Accepted March 15, 1983. 
ski, '81a,b; Bruce and Butler, '81). In turtles, the retinothalamofugal pathway consists of a projection from the retina to a thalamic nucleus termed the geniculatus lateralis, pars dorsalis (GLd), which in turn projects to a portion of the pallium of the telencephalon (Fig. 1) termed the dorsal cortex (cd; Hall and Ebner, '70b; Hall et al., 77; Desan, '81). Thalamic afferents from GLd terminate in the most superficial portions of the molecular layer of dorsal cortex upon the dendrites of dorsal cortex neurons. The turtle tectothalamofugal pathway consists of the projection of the retina to the tectum (Hall and Ebner, '70a; Bass and Northcutt, '81), with the tectum in turn projecting to the ipsilateral nucleus rotundus of the thalamus (Hall and Ebner, '70a; Foster and Hall, '75) and nucleus rotundus projecting to a distinct portion of the ipsilateral telencephalic dorsal ventricular ridge (DVR) termed the core nucleus (CN) by
Johnston ('15; Hall and Ebner, '70b; Balaban and Ulinski, ' $81 \mathrm{a}, \mathrm{b})$. The rotundorecipient portion of the core nucleus corresponds to zone 4 of the dorsal nucleus in the terminology of Balaban ('78; Balaban and Ulinski, '81b). The retinal projection to the tectum terminates within superficial layers of the turtle tectum, while the projection to nucleus rotundus arises from a deeper layer of the tectum, the stratum griseum centrale (unpublished observations). The projection of nucleus rotundus to the $\mathrm{CN}$ is limited to that portion of the $\mathrm{CN}$ at or anterior to the level of the anterior commissure. Both the $\mathrm{CN}$ and the dorsal cortex have been found by electrophysiological techniques to show short latency (40-80 msec) visual responsivity (Orrego, '61; Dunser et al., '81). The circuity of the retinothalamofugal and tectothalamofugal visual pathways in turtles is similar to that of the retinothalamofugal and tectothalamofugal vi-

$\begin{array}{llll} & & \text { Abbreviations } & \\ \mathrm{cd} & \text { Cortex dorsalis } & \text { LP } & \text { Lobus parolfactorius } \\ \mathrm{cdm} & \text { Cortex dorsomedialis } & \text { NCA } & \text { Nucleus commissuralis anterioris } \\ \mathrm{cm} & \text { Cortex medialis } & \text { NDB } & \text { Nucleus fasciculus diagonalis Brocae } \\ \mathrm{CN} & \text { Core nucleus } & \text { PA } & \text { Paleostriatum augmentatum } \\ \text { CO } & \text { Chiasma opticum } & \text { PC } & \text { Paleostriatal complex } \\ \text { cp } & \text { Cortex pyriformis } & \text { PT } & \text { Pallial thickening } \\ \text { DVR } & \text { Dorsal ventricular ridge } & \text { R } & \text { Nucleus rotundus } \\ \text { FPL } & \text { Fasciculus prosencephli lateralis (lateral forebrain bundle) } & \text { Tel } & \text { Telencephalon } \\ \text { GLd } & \text { Nucleus geniculatus lateralis pars dorsalis } & \text { TeO } & \text { Tectum opticum } \\ \text { GP } & \text { Globus pallidus } & & \end{array}$

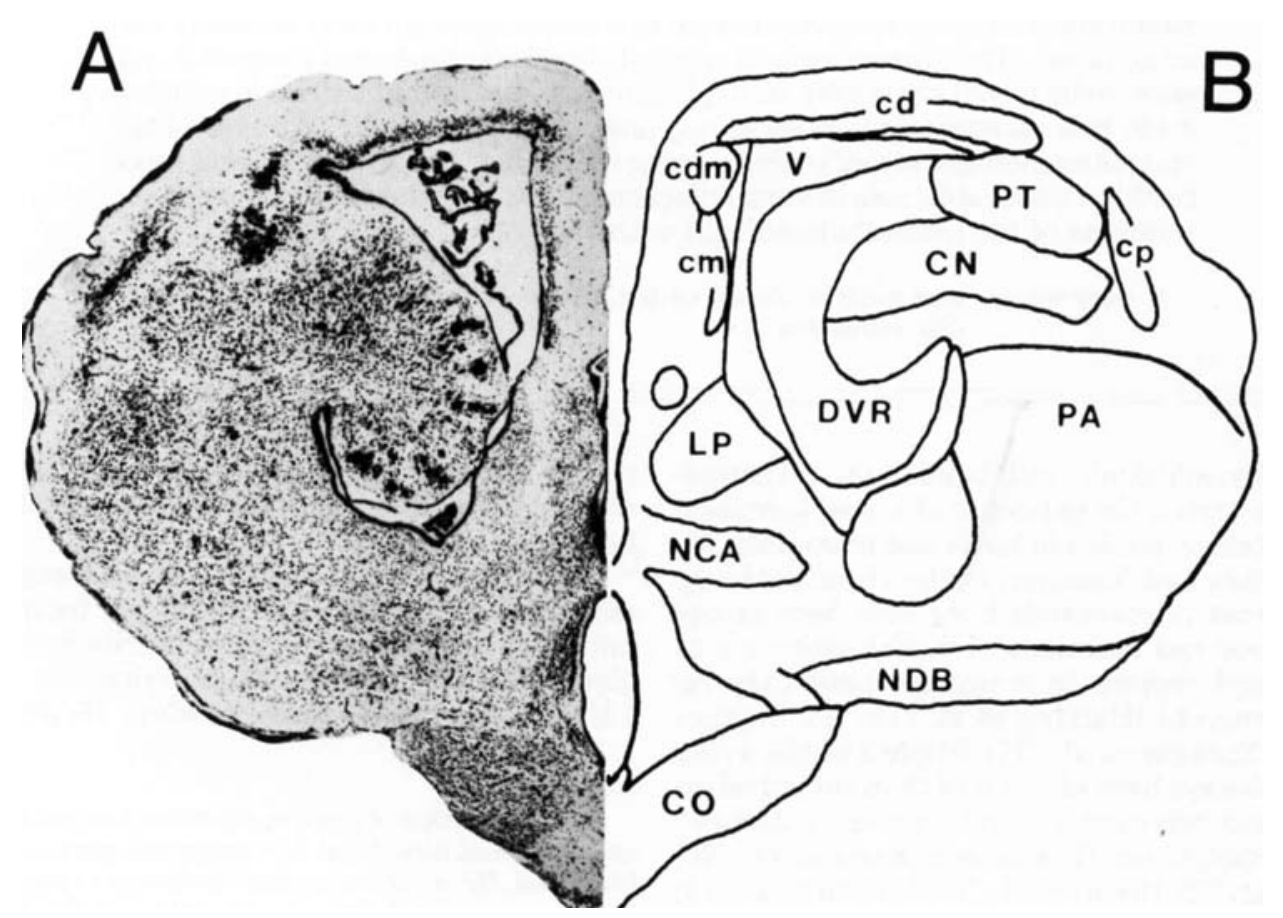

Fig. 1. Photomicrograph (A) and line drawing (B) of a transverse section through turtle brain at the level of the anterior commissure. The dorsal ventricular ridge (DVR), the core nucleus (CN) of the dorsal ventricular ridge, and the dorsal cortex (cd) are evident at this level. 

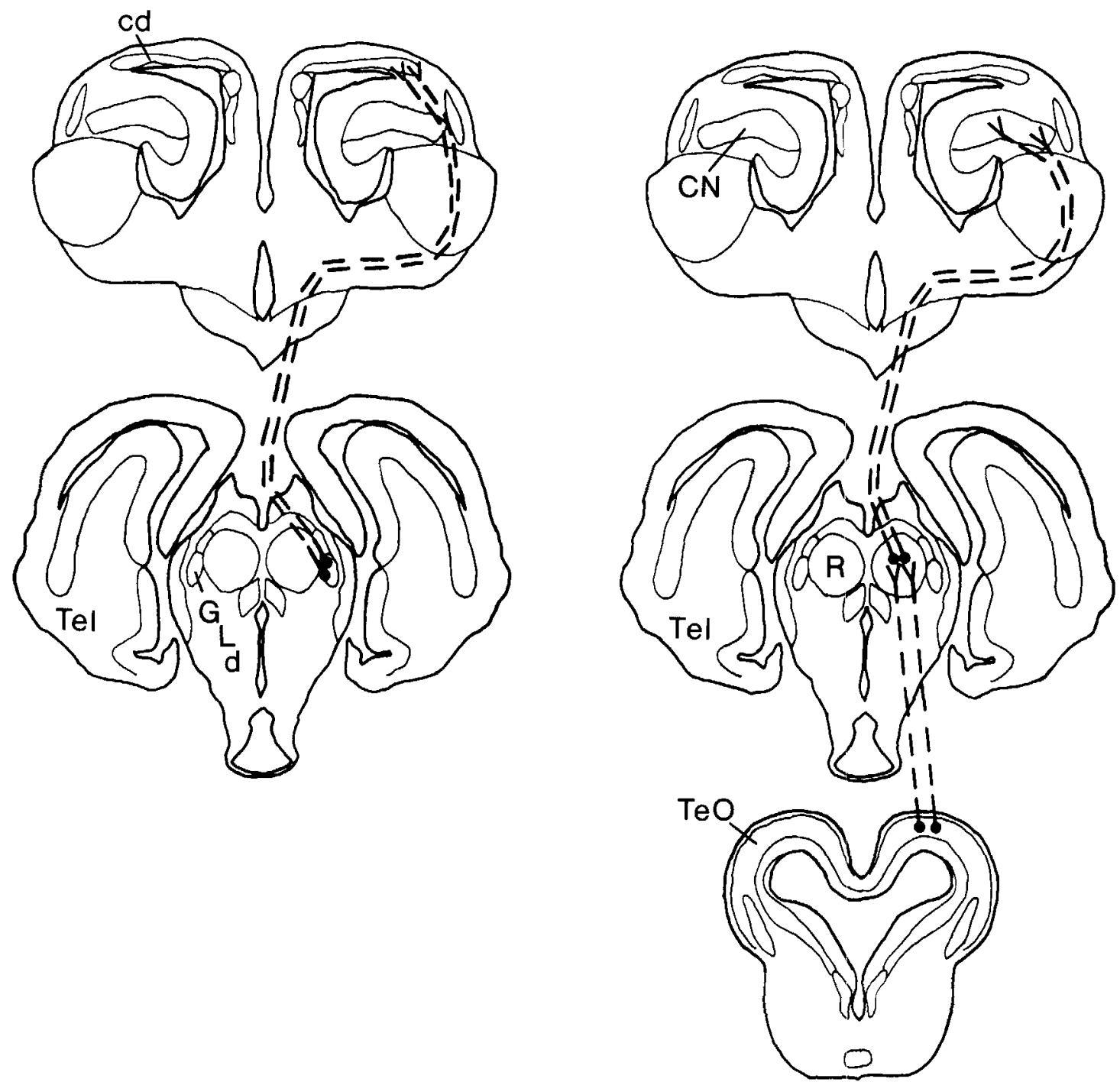

Fig. 2. Schematic representation of the components of the retinothalamofugal (left) and the tectothalamofugal (right) visual pathways of the turtle. The line drawings are based on transverse sections through the brain of turtle. The retinal projection to the tectum and the dorsal lateral geniculate nucleus (GLd) is nearly entirely crossed in turtle. The retinothalamofugal visual pathway consists of the following serially connected

sual pathways in birds, respectively (Karten, '79). The visual pathways to the telencephalon in turtle are illustrated in Figure 2.

Although behavioral studies in birds have shown that lesions of any of the forebrain components of the ascending visual lemniscal pathways result in impairments in the performance of a variety of visual tasks, investigation of the functions of the forebrain components of the visual pathways in reptiles has been limited. The literature on behavioral investigations of the visual functions of the reptilian telencephalon has been extensively reviewed by Belekhova ('79) ${ }^{2}$ and Peterson ('80). Diebschlag ('38), in a large study on the effects of telencephalic ablation in Lacerta, noted one lizard that had sustained a bilateral lesion of the structures: the retina-the dorsal lateral geniculate nucleus of the thalamus - the visual dorsal cortex of the telencephalon. The tectothalamofugal visual pathway consists of the following serially connected structures: the tectum of the midbrain - nucleus rotundus of the thalamus - the core nucleus of the telencephalon. anterior two-thirds of the dorsal ventricular ridge (including the rotundorecipient zone presumably) and was deficient in the retention of a color discrimination. Unfortunately, few details were given on the telencephalic regions damaged or on the training conditions. More recently, Bass et al. ('73) found no effect of dorsal ventricular ridge

${ }^{2}$ Belekhova ('79) has reviewed the extensive Russian literature on the reptilian telencephalon. Since nearly the entirety of this literature is in Russian, the review by Belekhova represents our only access to this information. References to Belekhova ('79) in this paper in many cases refer to specific experiments that had been reported in Russian and are summarized by Belekhova ('79). 
lesions or of dorsal cortex lesions on visual discriminative performance in the side-necked turtle (Podocnemis unifilis). Peterson ('80) also found no effect of dorsal cortex lesions on the ability of the lizard Dipsosaurus to discriminate visual intensity differences. Similarly, Hertzler and Hayes ('67) found no effect of dorsal cortex lesions on either optokinetic nystagmus or visual cliff choices in turtle. Reiner and Powers ('78), however, have shown that lesions of the thalamic component of the tectothalamofugal visual pathway in turtles (nucleus rotundus) severely impair turtles in their ability to perform visual discriminative tasks. More recently, Reiner and Powers ('80) have noted that lesions of the basolateral telencephalon also severely impair turtles in their ability to perform visual discriminative tasks. In that paper, we suggested that impairments observed after basolateral telencephalic lesions might have their basis in the destruction of the fibers of the ascending visual pathways of turtles. Axons of both the tectothalamofugal and retinothalamofugal pathways course through the basolateral telencephalon in turtles (Hall and Ebner, '70b; Balaban and Ulinski, '81a,b). Although our data implied that anatomically definable telencephalic visual areas in turtle play a major role in visual functions, previous behavioral studies by others had not shown such a role for either the $\mathrm{CN}$ or dorsal cortex. Using more sensitive behavioral methods than previously used by others in the study of telencephalic visual functions in turtles, we reexamined the effects of extensive lesions of either the core nucleus or the dorsal cortex on visual discriminative performance.

\section{MATERIALS AND METHODS Subjects}

Thirty native eastern painted turtles (Chrysemys picta picta), both male and female, were used. The turtles were full-grown adults, $10-15 \mathrm{~cm}$ in carapace length and $200-$ $400 \mathrm{gm}$ in weight. Subjects were maintained in individual open aquaria in a room with a controlled temperature set at $30^{\circ} \mathrm{C}$. An artificial day-night cycle, consisting of 14 hours light and 10 hours darkness, was controlled automatically. Further details of the housing and care are presented elsewhere (Reiner and Powers, '78).

\section{Apparatus}

The apparatus was adapted from that used by Pert and Gonzalez ('74). The apparatus consisted of a watertight black Plexiglas enclosure, with a hinged top made of black Plexiglas. Centrally located on the front wall of the chamber was a translucent disk, whose center was $7 \mathrm{~cm}$ above the floor of the chamber. Food reward (Gerber's Baby Beef) was delivered through an aperture in the center of the disk. Flanking this food magazine were two response keys, each a transparent plastic disk through which stimuli could be presented to the turtle inside the chamber via rearmounted projectors. Depressions of the response key were fed into standard programming equipment that controlled and recorded the events in the experimental chamber. Further details of the experimental apparatus are presented elsewhere (Reiner and Powers, '78).

\section{Procedure}

Preoperative behavioral training. Throughout the experiment, turtles received only one training session per day, consisting of 20 reinforcements. Each reinforcement consisted of the delivery of $0.3 \mathrm{ml}$ of Gerber's Baby Beef and was accompanied by a 15-second illumination of the food magazine. During a training session, the chamber was illuminated by a houselight in the chamber and was filled to a depth of $2.5 \mathrm{~cm}$ with water.

Following food magazine training and key training, turtles were shifted to experimental discrimination training. Fifteen turtles were trained on a visual intensity problem and 15 were trained on a pattern problem. The stimuli for the intensity problem were two circular, evenly illuminated areas $(3.2 \mathrm{~cm}$ in diameter), with a $0.4-\log$-unit difference in luminance between them. This difference was achieved by using a Kodak 96, 0.6 neutral density filter to attenuate the light intensity for one stimulus and a Kodak 96, 0.2 neutral density filter to attenuate the light intensity for the other stimulus. The intensity difference and the uniformity of illumination were verified photometrically using a Simpson illumination meter (model 408). The pattern problem stimuli were two circular areas $(3.2 \mathrm{~cm}$ in diameter) of a black background with three superimposed white stripes. For one of the stimuli the stripes were vertically oriented, while for the other the stripes were horizontally oriented. The stimulus pair was equated for the intensity of the white lines by choosing projector bulbs that resulted in matching stimulus intensity, as measured by a Simpson illumination meter (model 408).

The experimental training paradigm was a simultaneous discrimination, with a limited correction procedure for errors. Four repetitive errors were allowed before a guidance trial was given. Stimuli varied in their left-right position according to a random order, each stimulus appearing an equal number of times in either position. The ITI (intertrial interval) was 15 seconds, with responses during the ITI resetting the ITI timer. The response requirement for both correct and incorrect responses was FR2 (fixed ratio). On the intensity problem, seven turtles were trained with bright-correct and eight with dim-correct. On the pattern problem, six turtles were trained with vertical-correct and nine with horizontal-correct. Training on either problem was continued until criterion performance was achieved. For the pattern problem, a turtle was considered to have achieved criterion when it performed at $90 \%$ correct for 2 consecutive days. For the intensity problem, a turtle was considered to have achieved criterion when it performed at $80 \%$ correct for 2 consecutive days. The difference in criterion level for the two discriminative tasks reflects an at tempt to make the problems of a more comparable level of difficulty. Preliminary work had indicated that the pattern problem was learned to an $80 \%$ correct level much more quickly than the intensity problem. An intensity difference of $0.4 \mathrm{log}$ units is near the intensity difference threshold of turtles in the experimental conditions used in the present study (54 lux experimental chamber illumination and 32 candles $/ \mathrm{m}^{2}$ intensity for brighter stimulus; Powers and Frank, '80, '83). In the determination of performance level for a given day, only responses on the initial presentation of a stimulus pair were used. Responses during repetitive presentation of a stimulus pair were recorded, but not used in data analysis. Our behavioral procedures are described in greater detail elsewhere (Reiner and Powers, $78)$.

Surgery. Surgery was performed within 3 days after criterion was achieved. Eight turtles that had been trained on the intensity problem (four bright-correct and four dimcorrect) and eight turtles that had been trained on the pattern problem (three vertical-correct and five horizontalcorrect) received lesions aimed at the $\mathrm{CN}$. Coordinates were obtained from the stereotaxic atlas of the turtle brain 
of Powers and Reiner ('80). Target coordinates were restricted to the portion of the $\mathrm{CN}$ at or anterior to the anterior commissure (A4.0-A3.4), i.e., that portion of the $\mathrm{CN}$ in receipt of input from nucleus rotundus (Hall and Ebner, '70b; Balaban and Ulinski, '81a,b). Turtles were anesthetized with Equithesin (I.M.: dose $.20 \mathrm{ml} / 100 \mathrm{gm}$ body weight). The skull was opened with a dental drill and the lesions were made electrolytically by passing a $2.0-\mathrm{mA}$ anodal current for 20 seconds. Electrodes were standard size 0 insect pins, insulated with Formvar up to 0.5 from the tip. All lesions were made bilaterally. Since the $\mathrm{CN}$ is an extensive structure, two lesions (separated by $0.4 \mathrm{~mm}$ ) were placed in the $\mathrm{CN}$ of each hemisphere.

Among the remaining turtles (seven intensity discrimination turtles, three bright-correct and four dim-correct; seven pattern discrimination turtles, three vertical-correct and four horizontal-correct), 12 received aspiration lesions of the dorsal cortex while under Equithesin anesthesia. An attempt was made to aspirate only that portion of the dorsal cortex shown by Orrego ('61) to display visually evoked potentials (A4.4-A1.4). All dorsal cortex lesions were made bilaterally. Two turtles (one horizontal-correct and one dim-correct) received sham lesions in which the dorsal cortex was exposed but no tissue was aspirated.

Postoperative behavioral training. Following 3-6 days of postoperative recovery, turtles were retrained on the same discriminative problem they had learned preoperatively. All turtles were retrained to criterion or until the animal had received three times as many postoperative sessions as preoperative without having performed at criterion level on even a single postoperative day.

Histology. Subsequent to postoperative training, tur tles were anesthetized and perfused via the innominate artery with saline followed by Heidenhain's solution (without mercuric chloride). After several days' postfixation with the brain in situ, the brains of turtles in the CN lesion group were blocked in the plane of the atlas of Powers and Reiner ('80), removed from the skull, and embedded in gelatin-albumin. The brains were then sectioned at $25 \mu \mathrm{m}$ on a freezing microtome, mounted on slides, and stained with cresyl violet. The brains of turtles in the dorsal cortex group were also postfixed with the brain in situ for several days, but after blocking and removal from the skull, the brains were dehydrated through graded alcohols, cleared in xylene, and embedded in paraffin. These brains were then sectioned at $15 \mu \mathrm{m}$ on a rotary microtome, mounted on slides, and stained with cresyl violet.

The CN lesions were reconstructed on standard sections from the atlas of Powers and Reiner ('80). Areal tissue damage to the $\mathrm{CN}$, to a variety of structures adjacent to $\mathrm{CN}$, and to brain tissue per se were hand measured for each section. The areal measurements were used to calculate for each animal (1) the total volume of the rotundorecipient portion of $\mathrm{CN}$ destroyed, (2) the volume of tissue damage to structures adjacent to $\mathrm{CN}$, and (3) the total volume of brain tissue destroyed. The volume of the rotundorecipient portion of the $\mathrm{CN}$ destroyed compared to the total volume of rotundorecipient $\mathrm{CN}$ was used to determine the percentage of $\mathrm{CN}$ destroyed.

Lesions of the dorsal cortex were largely confined to the pallial roof of the telencephalon. Accordingly, dorsal cortex lesions were reconstructed on surface view drawings of the turtle cerebral hemispheres, as well as on standard sections from the atlas of Powers and Reiner ('80). The data of
Orrego ('61) and Hall and Ebner ('70b) were used to define the visual portion of the dorsal cortex. A Talos digitizing tablet peripheral to a Terak series 8500 microcomputer was used to measure (from the surface view reconstructions): (1) the total pallial area destroyed and (2) the total area of visual dorsal cortex destroyed. Based on the total area of the visual portion of the dorsal cortex, the percentage of the visual dorsal cortex destroyed was calculated for each turtle. The amount of damage to subcortical structures was also determined for the dorsal cortex lesion turtles.

\section{RESULTS \\ Anatomical}

Tables 1-4 indicate the amount of damage to various cell groups of the telencephalon in the turtles in the core nucleus lesion groups (Tables 1,2) and the dorsal cortex lesion groups (Tables 3,4 ). In addition, the amount of overall tissue damage (expressed in cubic millimeters) is indicated for each turtle. Based on the amount of tissue damage to the target structure, turtles were assigned to separate lesion categories. The limits for inclusion in these lesion categories were intended as devices to aid in grouping the animals for the presentation of the preoperative and postoperative learning curves.

Core nucleus lesions-intensity discrimination turtles. Turtles trained on the intensity problem were divided into three lesion categories: (1) severe core nucleus destruction (greater than $65 \%$ bilateral core nucleus destruction), (2) moderate core nucleus destruction $(40-65 \%$ bilateral core nucleus destruction), and (3) slight core nucleus destruction $(0-40 \%$ core nucleus destruction). Figure 3 presents the lesion reconstruction for a representative turtle in each lesion category. Turtles are listed in Table 1 in terms of the percentage of damage to the core nucleus. Turtle 19 , which sustained no core nucleus damage, is listed with turtle 42 , which sustained slight core nucleus damage. In turtle 63 in the severe core nucleus lesion category, the right core nucleus was not directly damaged, the lesion being in the lateral portion of the paleostriatum augmentatum (PA). This lesion did, however, extensively damage the lateral forebrain bundle, which contains the fibers of the rotundo-core nucleus pathway. In the nucleus rotundus ipsilateral to this PA lesion, a $75 \%$ cell loss was observed. Consequently, for the right side in turtle 63 core nucleus damage was scored as $75 \%$, since at least $75 \%$ of the rotundal afferents of this core nucleus had been removed. No retrograde degeneration was evident in the nucleus rotundus ipsilateral to lesions in any of the remaining turtles in the core nucleus lesion categories; lesions in these turtles were largely restricted to the dorsal ventricular ridge.

As can be seen in Table 1, core nucleus damage was attended by varying amounts of damage to adjacent structures, including the visual dorsal cortex, pallial thickening, the paleostriatum augmentatum and the portions of the anterior dorsal ventricular ridge (Balaban, '78) lying outside of the rotundorecipient zone (core nucleus) of the anterior dorsal ventricular ridge. Damage to the dorsal cortex tended to be minimal, with only turtles 57 and 44 showing as much as moderate dorsal cortex damage. In general, dorsal cortex damage was restricted to rostral portions of the visual portion of the dorsal cortex. Damage to the right dorsal cortex and pallial thickening in turtle 63 is scored as severe since the basolateral forebrain damage in this turtle 
TABLE 1. Behavioral Performance (Expressed as \% Saving Score) and Lesion Damage for the Core Nucleus Turtles Trained on the Visual Intensity Problem ${ }^{1}$

\begin{tabular}{|c|c|c|c|c|c|c|c|}
\hline Turtle & $\begin{array}{c}\% \\
\text { savings }\end{array}$ & $\begin{array}{c}\% \\
\mathrm{CN}_{\mathrm{L}} / \mathrm{CN}_{\mathrm{R}} \\
\end{array}$ & $\begin{array}{l}\text { Total } \\
\text { mass }^{2}\end{array}$ & $\mathrm{PC}_{\mathrm{L}} \mathrm{PC}_{\mathrm{R}}$ & $\mathrm{cd}_{\mathrm{L}} / \mathrm{cd} \mathrm{d}_{\mathrm{R}}$ & $\mathrm{PT}_{\mathbf{L}} / \mathrm{PT}_{\mathrm{R}}$ & $\mathrm{DVR}_{\mathrm{L}} / \mathrm{DVR}_{\mathrm{R}^{3}}$ \\
\hline 63 & $<-122$ & $90 / 75$ & 12.53 & $* / *$ & $-1 * * *$ & $* * / * * *$ & $* * / * *$ \\
\hline 44 & -233 & $93 / 100$ & 16.77 & $* / * *$ & $* * / *$ & $* * / * *$ & $* * / * *$ \\
\hline 67 & -111 & $71 / 65$ & 4.13 & $* / *$ & $-1-$ & $* 1-$ & $* * / * *$ \\
\hline 57 & -3 & $92 / 100$ & 12.02 & $* / *$ & $* * / *$ & $* * / * *$ & $* * / *$ \\
\hline 59 & -32 & $60 / 64$ & 7.11 & $* / *$ & $* / *$ & $* / * *$ & $* 1-$ \\
\hline 58 & +41 & $40 / 60$ & 7.18 & $* * / *$ & $* /-$ & $* 1-$ & $* * / * *$ \\
\hline 19 & +82 & $0 / 0$ & 1.00 & $-1-$ & $-1-$ & $-1-$ & $-1-$ \\
\hline 42 & +100 & $35 / 50$ & 3.14 & $-1-$ & $-1^{*}$ & $* / *$ & $-1-$ \\
\hline
\end{tabular}

'The table quantifies the percentage bilateral damage to the rotundorecipient portion of the core nucleus and the total amount of brain tissue destroyed. The relative amounts of bilateral damage to the paleostriatal complex (PC; including PA and GP, A5.0A3.0), the visual dorsal cortex, the pallial thickening, and the nonrotundorecipient portion of the anterior DVR are shown. Three asterisks, severe damage; two asterisks, moderate damage; one asterisk, slight damage; -, negligible damage. The dorsal cortex leterisks, severe damage; two asterisks, moderate damage; one asterisk, slight damage; -, negligible damage. The dorsal cortex le-
sion categories were defined as in the case of the dorsal cortex lesion turtles. For the other structures, severe damage was greater than $65 \%$, moderate damage was $30-65 \%$, and slight damage was $5-30 \%$. L, left; R, right. Other abbreviations as in list preceding

Figure 1 .
${ }^{2}$ In $\mathrm{mm}^{3}$.

${ }^{3}$ Denotes portion of DVR lying outside of core nucleus.

TABLE 2. Behavioral Performance (Expressed as \% Saving Score) and Lesion Damage for the Core Nucleus Turtles Trained on the Pattern Problem ${ }^{1}$

\begin{tabular}{|c|c|c|c|c|c|c|c|}
\hline Turtle & $\begin{array}{c}\% \\
\text { savings }\end{array}$ & $\begin{array}{c}\% \\
\mathrm{CN}_{\mathrm{L}} / \mathrm{CN}_{\mathrm{R}}\end{array}$ & $\begin{array}{l}\text { Total } \\
\text { mass }^{2}\end{array}$ & $\mathrm{PC}_{\mathrm{L}} \mathbf{P C}_{\mathrm{R}}$ & $\mathrm{cd}_{\mathrm{L}} / \mathrm{cd}_{\mathrm{R}}$ & $\mathrm{PT}_{\mathrm{L}} / \mathrm{PT}_{\mathrm{R}}$ & $\mathrm{DVR}_{\mathrm{L}} / \mathrm{DVR}_{\mathrm{R}}{ }^{3}$ \\
\hline 35 & $<-200$ & $90 / 88$ & 5.83 & $* * / *$ & $* / * *$ & $* / * *$ & $* / *$ \\
\hline 53 & -700 & $80 / 82$ & 4.38 & $* / *$ & $* / *$ & $* / *$ & $* 1-$ \\
\hline 50 & -340 & $100 / 95$ & 17.80 & $* * / * *$ & $-1-$ & $* * / * *$ & $* * / * *$ \\
\hline 49 & -200 & $85 / 40$ & 6.93 & $* * 1$ & $* / *$ & $* * * / *$ & $* * / *$ \\
\hline 37 & -175 & $25 / 48$ & 4.95 & $* / *$ & $-1-$ & $* / *$ & $-1-$ \\
\hline 52 & -20 & $16 / 19$ & 3.27 & $* 1-$ & $* / *$ & $* / *$ & $-1^{*}$ \\
\hline 66 & $<-200$ & $97 / 0$ & 4.12 & $* * * / *$ & $-1-$ & $* 1-$ & $* 1-$ \\
\hline 36 & +88 & $72 / 4$ & 8.71 & $* 1-$ & $-1-$ & $* 1-$ & $* * / * *$ \\
\hline
\end{tabular}

${ }^{1}$ See Table 1 footnote for further explanation.

${ }^{2}$ In $\mathrm{mm}^{3}$.

${ }^{3}$ Denotes portion of DVR lying outside of core nucleus.

TABLE 3. Behavioral Performance (Expressed as \% Savings Score) and Lesion Damage in Turtles in the Dorsal Cortex Iesion Groups Trained on the Visual Intensity Problem ${ }^{1}$

\begin{tabular}{|c|c|c|c|c|c|c|}
\hline Turtle & $\begin{array}{c}\% \\
\text { savings }\end{array}$ & $\mathrm{CN}_{\mathrm{L}} / \mathrm{CN}_{\mathrm{R}}$ & $\begin{array}{l}\text { Total } \\
\text { mass }^{2}\end{array}$ & $\mathrm{~cd}_{\mathrm{L}} / \mathrm{cd}_{\mathrm{R}}$ & $\mathrm{PT}_{\mathrm{L}} / \mathrm{PT}_{\mathrm{R}}$ & $\mathrm{DVR}_{\mathrm{L}} / \mathrm{DVR}_{\mathrm{R}}{ }^{3}$ \\
\hline E57 & +88 & $-l^{* *}$ & 21.74 & $84 / 92$ & $* * * / * * *$ & $-1-$ \\
\hline E93 & +100 & $-1-$ & 4.65 & $58 / 45$ & $-1-$ & $-1-$ \\
\hline E50 & +29 & $* / *$ & 3.10 & $57 / 16$ & $* * / * *$ & $-1-$ \\
\hline E72 & -38 & $-1-$ & 3.04 & $51 / 49$ & $-1-$ & $-1-$ \\
\hline E59 & +75 & $-1-$ & 2.90 & $6 / 32$ & $-1-$ & $-1-$ \\
\hline E95 & +67 & $-1-$ & 1.62 & $0 / 22$ & $-1-$ & $-1-$ \\
\hline E64 & +50 & $-1-$ & 0.0 & $0 / 0$ & $-1-$ & $-1-$ \\
\hline
\end{tabular}

${ }^{1}$ The table quantifies the percentage bilateral damage to the dorsal cortex and the overall amount of brain tissue destroyed. The relative amounts of bilateral destruction of the pallial thickening, core nucleus, and nonrotundorecipient dorsal ventricular ridge are also shown. The asterisks (and the dashes) are defined as in the footnotes to Table 1 . The core nucleus lesion categories were defined as in the case of the core nucleus lesion turtles while the categories for other structures are as defined in Table 1.

${ }^{3}$ Denotes portion of DVR lying outside of core nucleus.

TABLE 4. Behavioral Performance (Expressed as \% Savings Score) and Lesion Damage in Turtles in the Dorsal Cortex Lesion Group Trained on the Pattern Problem'

\begin{tabular}{|c|c|c|c|c|c|c|}
\hline Turtle & $\begin{array}{c}\% \\
\text { savings }\end{array}$ & $\mathrm{CN}_{\mathrm{L}} / \mathrm{CN}_{\mathrm{R}}$ & $\begin{array}{l}\text { Total } \\
\text { mass }^{2}\end{array}$ & $\begin{array}{c}\% \\
\operatorname{cd}_{\mathrm{L}} / \mathrm{cd}_{\mathrm{R}} \\
\end{array}$ & $\mathrm{PT}_{\mathrm{L}} / \mathrm{PT}_{\mathrm{R}}$ & $\mathrm{DVR}_{\mathrm{L}} / \mathrm{DVR}_{\mathrm{R}^{3}}$ \\
\hline E11 & +100 & $-1-$ & 9.70 & $70 / 88$ & $-1-$ & $-1-$ \\
\hline E10 & +83 & $* * * /-$ & 5.13 & $56 / 30$ & $* * * /-$ & $-1-$ \\
\hline E6 & -33 & $* * / * *$ & 4.10 & $43 / 48$ & $* * * / * * *$ & $-1-$ \\
\hline E5 & +83 & $-1-$ & 3.40 & $33 / 36$ & $-1-$ & $-1-$ \\
\hline E13 & +100 & $-1-$ & 0.0 & $0 / 0$ & $-1-$ & $-1-$ \\
\hline E49 & +100 & $-1-$ & 1.42 & $20 / 0$ & $-1-$ & $-1-$ \\
\hline E53 & +60 & $-1-$ & 1.75 & $26 / 25$ & $-1-$ & $-1-$ \\
\hline
\end{tabular}

'See Table 3 footnote for further explanation.

${ }^{2}$ In $\mathrm{mm}^{3}$.

${ }^{3}$ Denotes portion of DVR lying outside of core nucleus. 
KEY

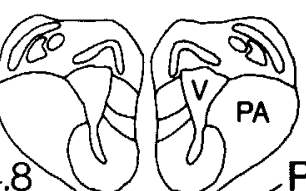

$\mathrm{A} 4.8 \mathrm{PT}$

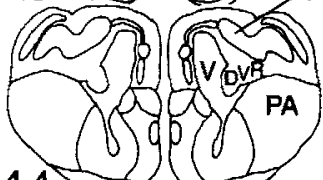

A4.4

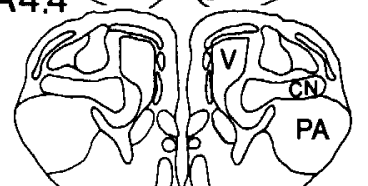

A4.0工

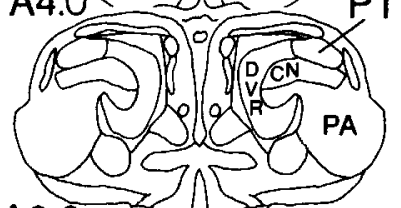

A3.
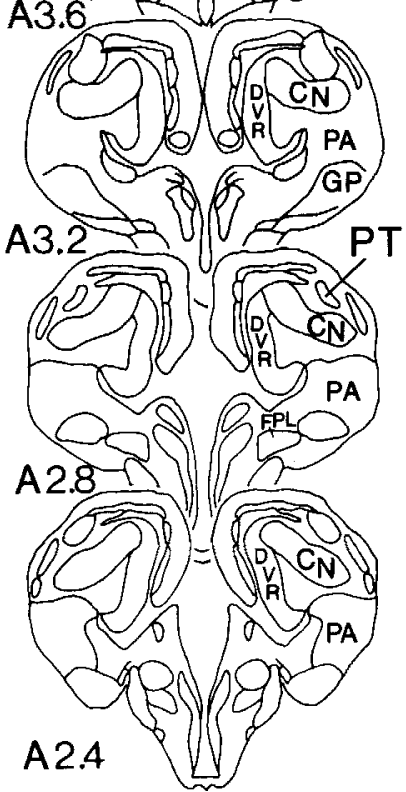

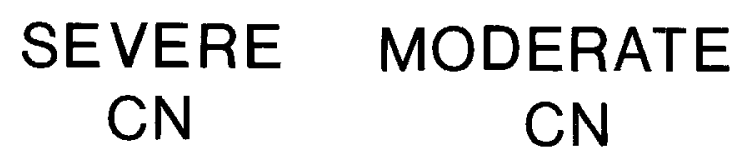

59

44
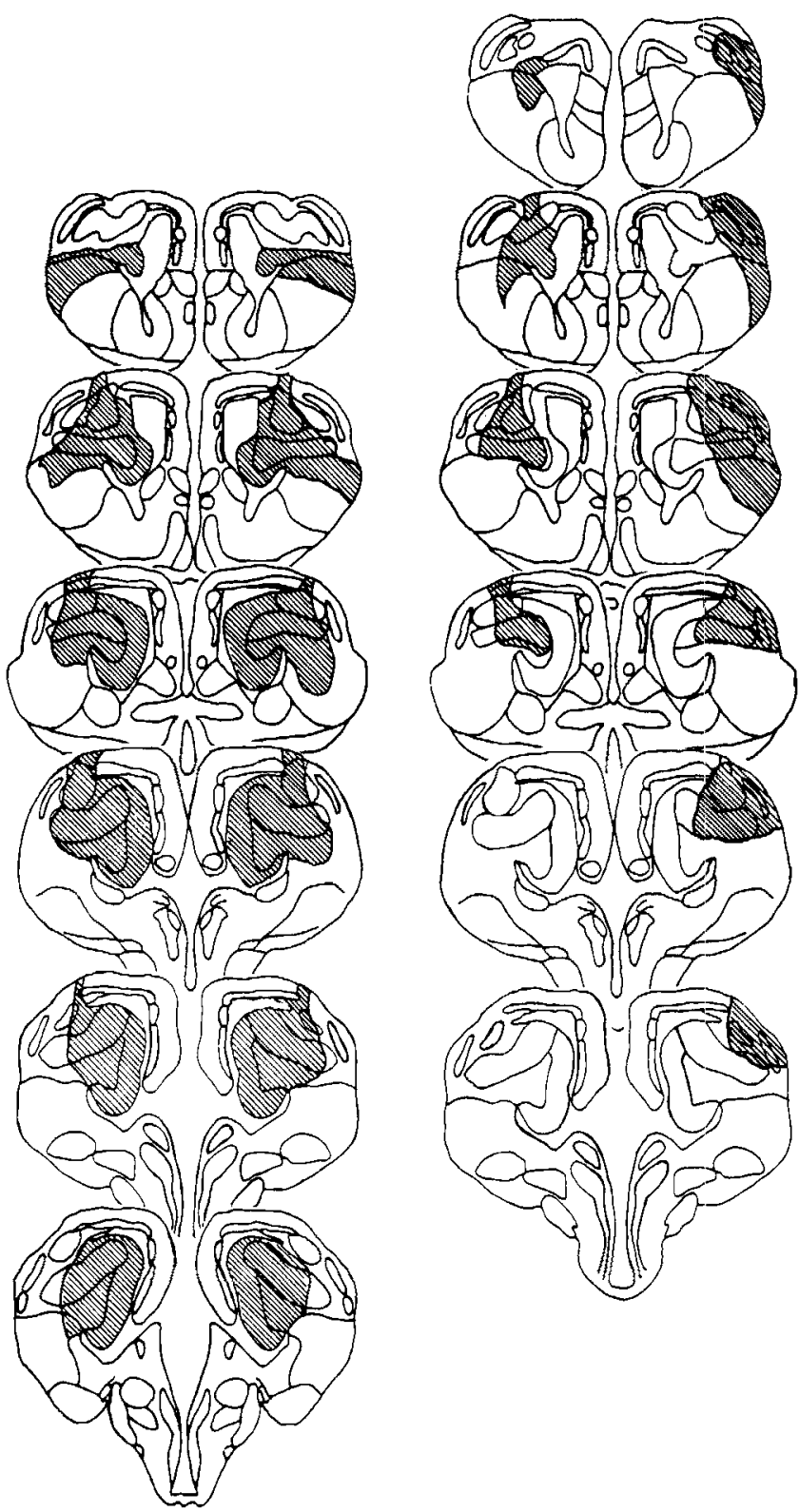

SLIGHT

$\mathrm{CN}$

42
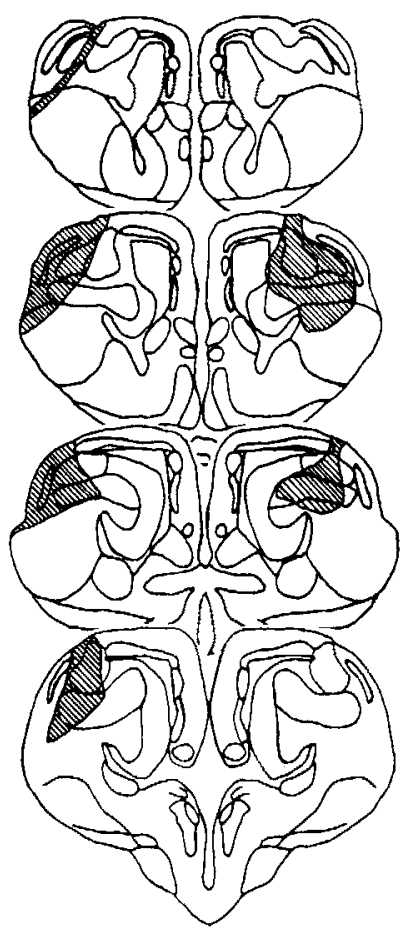

Fig. 3. Lesion reconstructions for representative turtles from each of the core nucleus lesion categories for the intensity discrimination group. The key shows drawings of transverse sections from the atlas of Powers and Reiner ('80). Rotundorecipient core nucleus extends from A4.0 to A3.4. 
KEY

SEVERE
CN

50

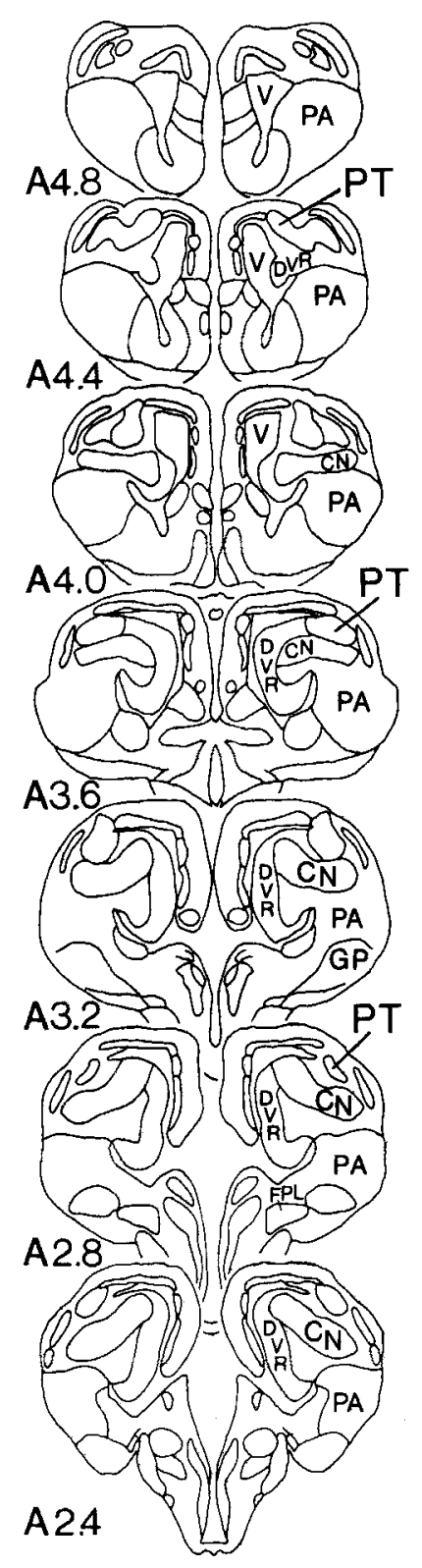

SLIGHT

$\mathrm{CN}$

37
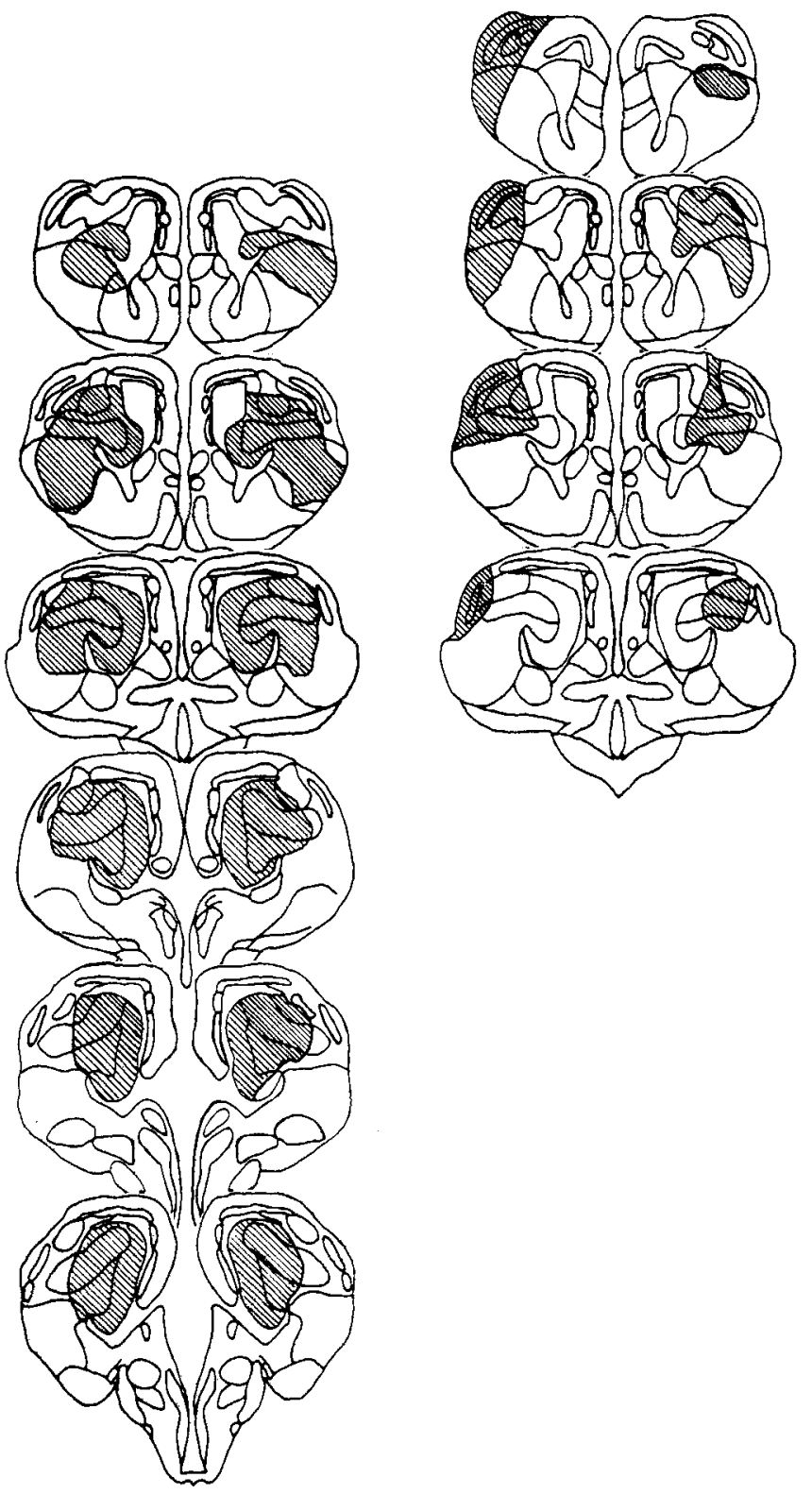

UNILAT.

$\mathrm{CN}$

36

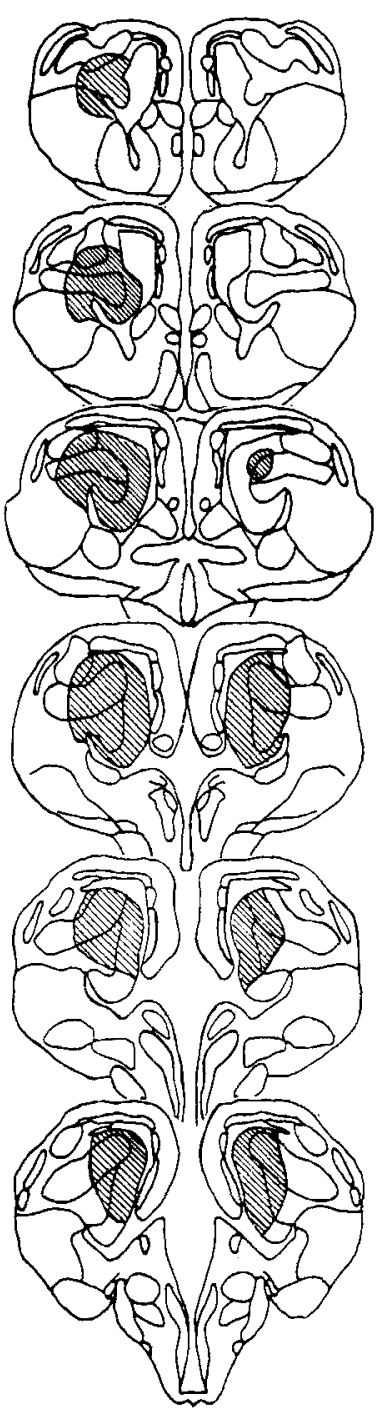

Fig. 4. Lesion reconstructions for representative turtles from each of the core nucleus lesion categories for the turtles trained on the pattern problem. Key from the atlas of Powers and Reiner ('80). Rotundorecipient core nucleus extends from A4.0 to A3.4. 
presumably severely damaged the ascending fibers of the geniculocortical (or retinothalamofugal) system. As can also be seen in Table 1, turtles with greater amounts of core nucleus damage tended also to have greater amounts of overall tissue damage. Statistical techniques were used to examine the correlation between the damage to these various structures and the behavioral impairments observed (see below).

Core nucleus lesions-pattern discrimination turtles. These turtles were divided into three lesion categories: (1) severe bilateral core nucleus destruction, (2) moderate and slight core nucleus damage, and (3) severe unilateral core nucleus damage. The limits for inclusion in these various categories were the same as in the case of the intensity dis. crimination turtles. Figure 4 depicts the lesion damage in a representative turtle in each lesion category. Table 2 presents the turtles classed in each of these lesion categories and shows the percentage of core nucleus damage. Turtles 36 and 66 were placed in a separate lesion category, termed severe unilateral core nucleus destruction, since both turtles sustained extensive rotundorecipient core nucleus damage on one side but negligible rotundorecipient core nucleus damage on the other.

Lesion damage in these turtles was well restricted to the core nucleus. Only one of the turtles sustained any more than slight dorsal cortex damage. In general, any damage to dorsal cortex was limited to rostral visual cortex. Unlike the intensity discrimination turtles, core nucleus damage in the pattern discrimination turtles did not appear to be correlated with total tissue damage. Of particular interest with respect to the evaluation of the role of the core nucleus in the behavioral impairments, turtles 36 and 50 (see Fig. 4) sustained similar amounts of extensive bilateral damage to portions of the DVR outside the core nucleus. These turtles differed, however, in that the rotundorecipient portion of the core nucleus was extensively damaged bilaterally in turtle 50 but only unilaterally damaged in turtle 36. As can be seen in Table 2, turtle 36 showed no be-
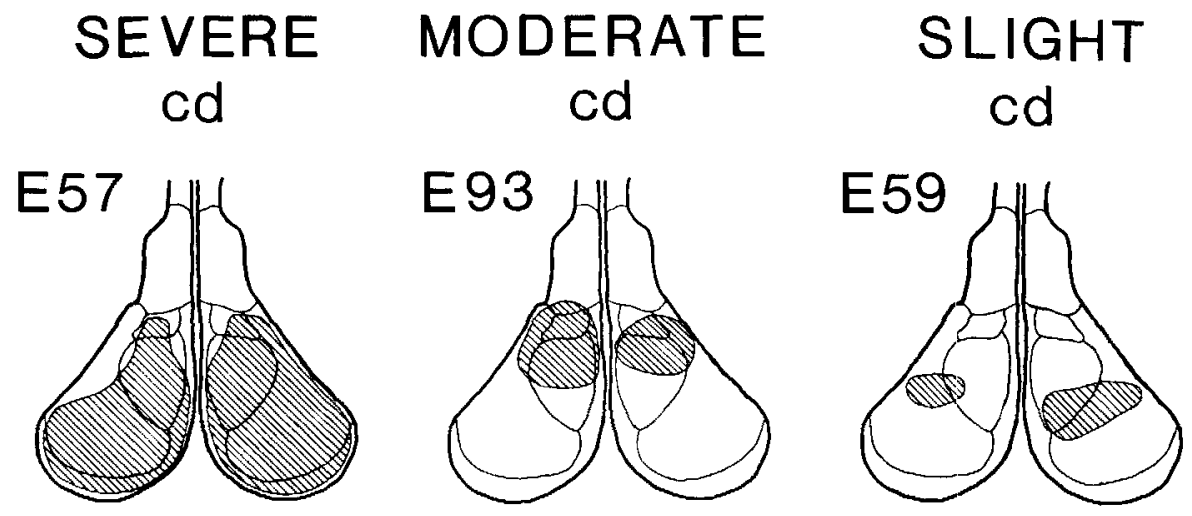
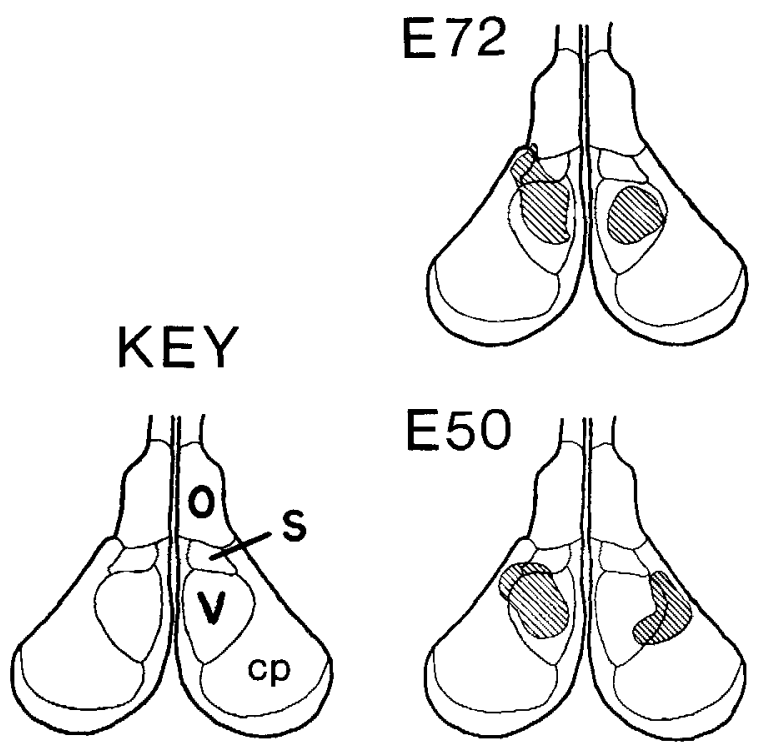

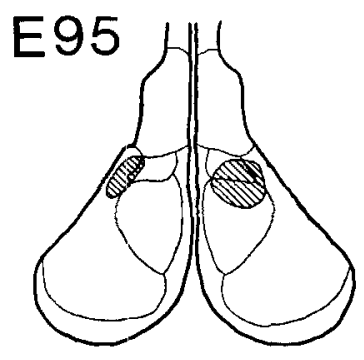

Fig. 5. Lesion reconstructions (as viewed from the dorsal aspect, with rostral toward the top of the page) for turtles in the dorsal cortex lesion categories that had been trained on the visual intensity problem. The drawings of the telencephalon and the extent of the various sensory areas are based on Orrego ('61) and Hall and Ebner ('70b). Note that the visual portion of the dorsal cortex extends from A4.4 to A1.4. Abbreviations: $\mathrm{O}$, ol factory bulb; S, somatosensory zone of the dorsal cortex; $V$, visual zone of the dorsal cortex; $\mathrm{cp}$, pyriform cortex. 


\section{KEY}

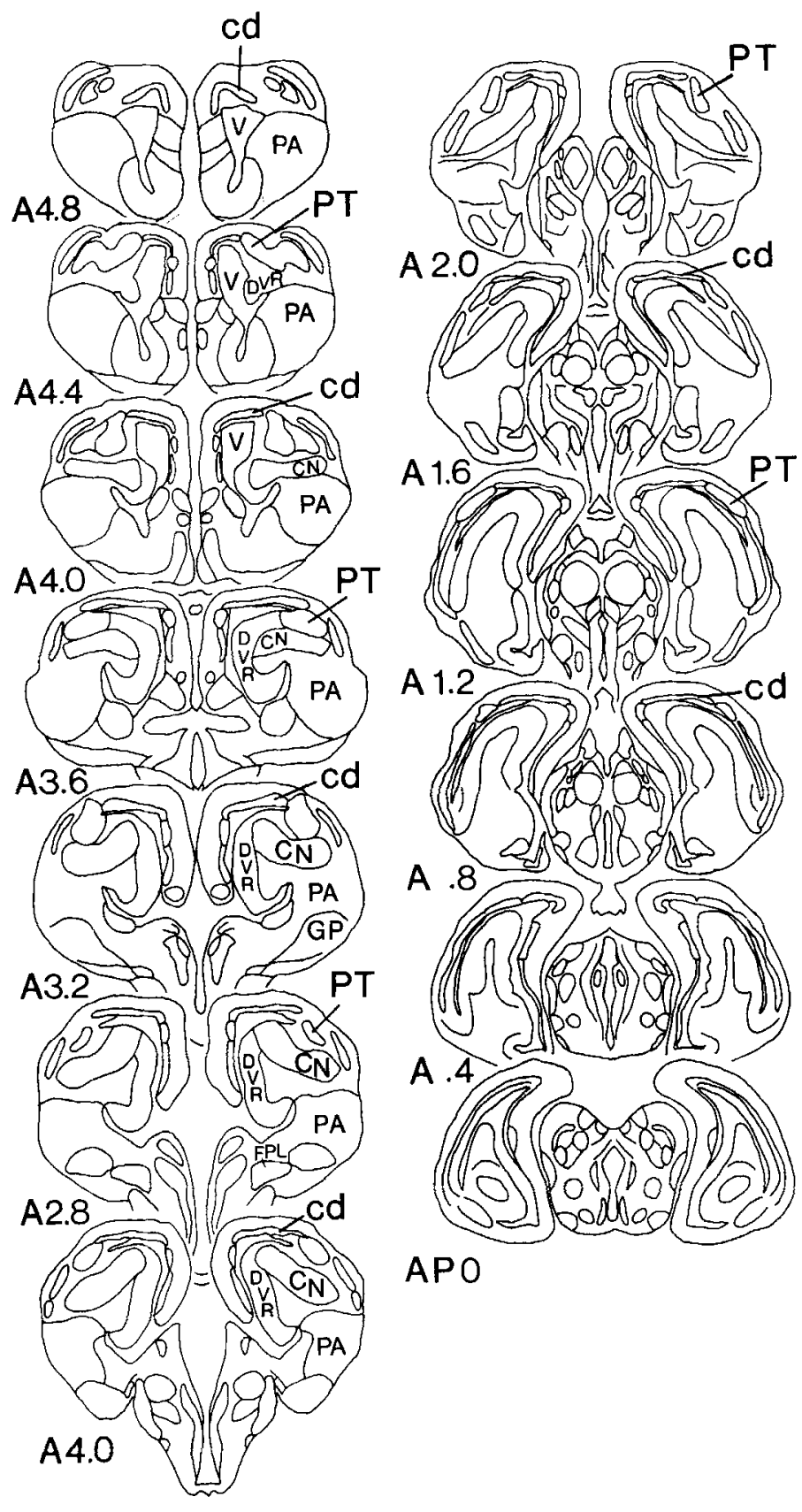

\section{SEVERE $\mathrm{cd}$}

E 57
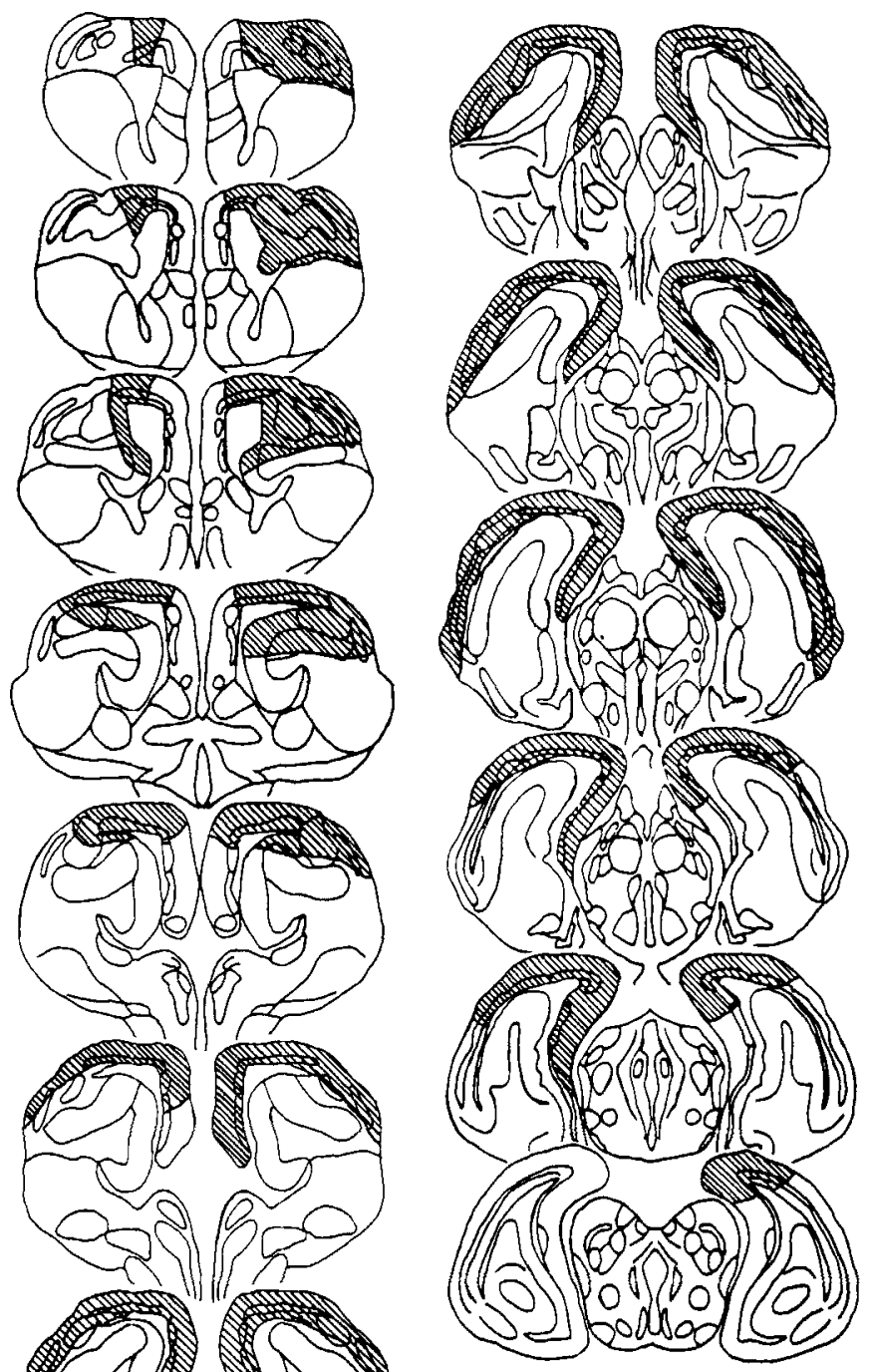

Fig. 6. Lesion reconstructions on transverse sections for the turtles shown in Figure 5 whose lesions impinged on subcortical structures. Note that the visual dorsal cortex extends from A4.4 to A1.4. 


\section{MODERATE cd}
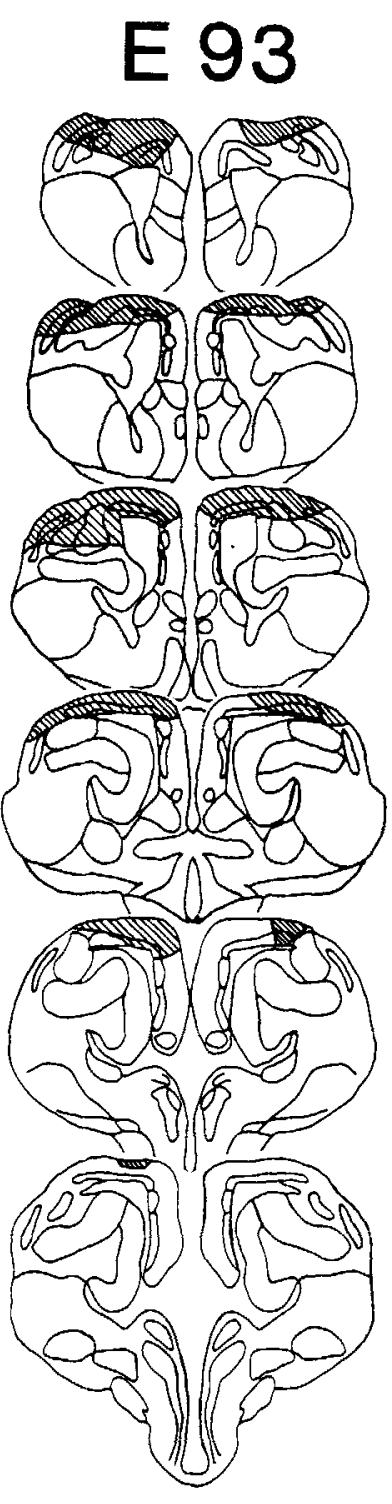

E 50
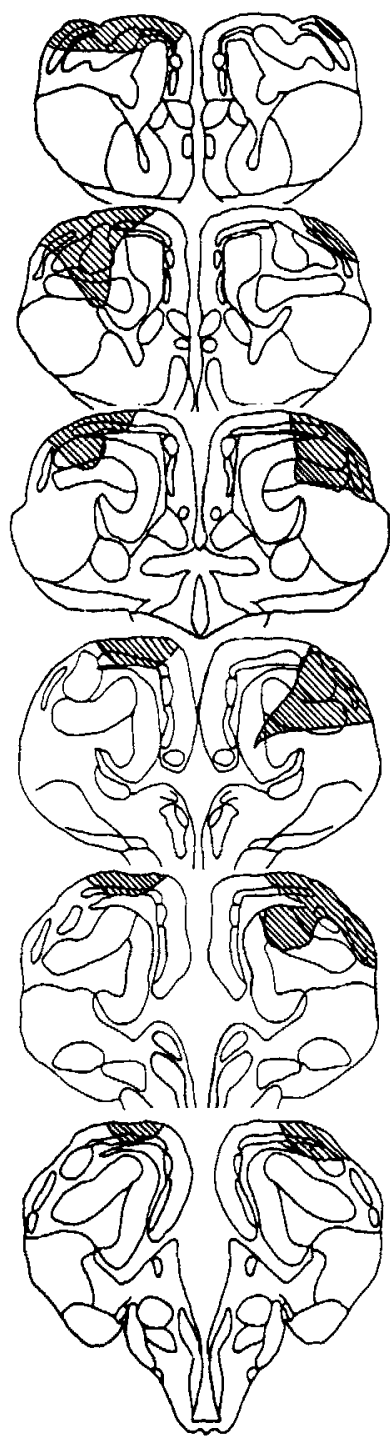

SLIGHT cd

E 59
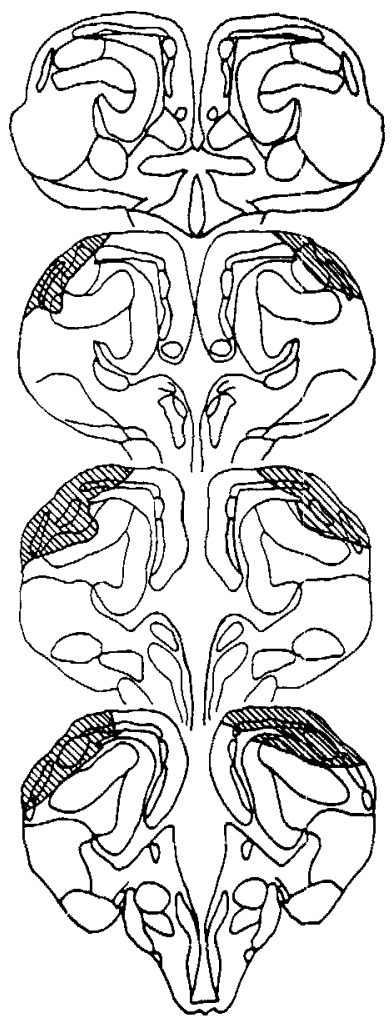

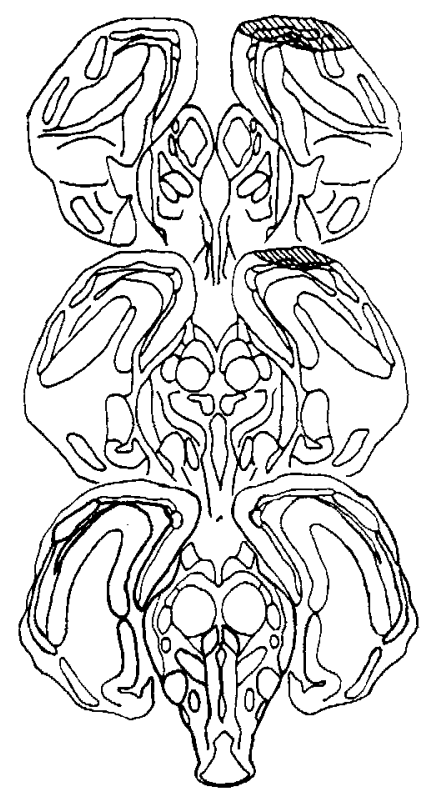

Figure 6 (continued) 
havioral impairment while turtle 50 was considerably impaired. Three turtles $(35,50$, and 49$)$ sustained moderate damage to the pallial thickening. The pallial thickening is continuous with the dorsal cortex and the dendrites of neurons of the medial pallial thickening appear to be in receipt of input from the retinothalamofugal pathway (Desan, ' 81 ; unpublished observations). Further, fibers of the retinothalamofugal pathway course lateral to the pallial thickening before terminating in the roof of the dorsal cortex. Consequently, damage to the pallial thickening may result in either direct or indirect damage to the retinothalamofugal system. The possible contribution of such damage to the behavioral impairments was considered in the case of all turtles in this study (see below).

Dorsal cortex lesions - intensity discrimination turtles. Three lesion categories were established: (1) severe dorsal cortex destruction (greater than $70 \%$ bilateral dorsal cortex destruction), (2) moderate dorsal cortex destruction (30-70\% bilateral dorsal cortex destruction), and (3) slight, or negligible, dorsal cortex destruction (5-30\%, or less, bilateral dorsal cortex destruction). Table 3 presents the percentage of dorsal cortex damage for each of these turtles. Figure 5 presents the lesion reconstructions for the dorsal cortex turtles in each of the lesion categories. Lesion reconstructions for the dorsal cortex turtles are presented from the dorsal view of the cerebral hemispheres in order to facilitate assessment of the amount of damage to the visual thalamorecipient portion of the pallium. The delineation of the visual portion of the pallium is based on Orrego ('61) and Hall and Ebner (70b). The surface view reconstructions also show the amount of damage to nonvisual portions of the cortex such as the olfactory cortex (pyriform cortex). Figure 6 presents lesion reconstructions for the turtles whose lesions impinged on subcortical structures.

In general, dorsal cortex turtles trained on the intensity problem sustained little damage to subcortical structures. Damage to the core nucleus and to the pallial thickening did occur in two turtles (see Fig. 6) and is indicated in Table 3. Damage to nonrotundorecipient portions of the DVR was negligible. The amount of total tissue damage is also shown. Turtle E64 received a sham lesion.

Dorsal cortex lesions - pattern discrimination turtles. Three lesion categories were established: (1) severe dorsal cortex destruction, (2) moderate dorsal cortex destruction, and (3) slight, or negligible, dorsal cortex destruction. The criteria for inclusion in these categories were the same as for the dorsal cortex turtles in the intensity distrimination group. Table 4 presents the percentage destruction of the visual dorsal cortex in these turtles. Figure 7 presents the lesion reconstructions for these seven turtles, as viewed from the dorsal aspect of the telencephalic hemispheres. Figure 8 presents the lesion reconstructions for several turtles whose lesions impinged on subcortical structures. Lesion damage was again well confined to the cortex. Turtles E10 and E6 sustained some damage to the core nucleus and pallial thickening (Fig. 8), as indicated in Table 4. Turtle E13 received a sham lesion.

\section{Behavioral}

Core nucleus lesion turtles. Turtles in the severe and moderate lesion categories for both discriminative tasks required several days to several weeks of remedial key training before experimental training could be resumed. Turtles were then retrained to criterion on their original discriminative problem. Some animals were unable, however, to reattain criterion-level performance and training was terminated. For all turtles a savings score was calculated according to the following formula:

savings $=100 \% \times \frac{\text { preoperative sessions }- \text { postoperative sessions }}{\text { preoperative sessions }}$

The last two criterion-level performance days were not included in the calculation of the savings score. The savings score for each turtle in the core nucleus lesion groups is presented in Tables 1 and 2. Figure 9 (intensity discrimination turtles) and Figure 10 (pattern discrimination turtles) present the preoperative and postoperative learning curves for each turtle in the core nucleus lesion group. Turtles are grouped in each set of curves in terms of the lesion category to which they had been assigned. Thus, for example, Figure $9 \mathrm{~A}$ and $\mathrm{B}$ show the learning curves for the turtles that had been trained on the intensity problem and were classed as having sustained severe core nucleus damage.

Among the turtles trained on the intensity problem, all four turtles in the severe core nucleus lesion category showed a postoperative loss in the retention of the discriminative problem, i.e., required more postoperative than preoperative trials to learn the discriminative problem. Turtle 63 received more than 60 postoperative sessions but never performed at criterion level $(80 \%$ correct) for even a single postoperative session. In contrast, only one of the two turtles in the moderate core nucleus category (turtle 59) and neither of the turtles in the slight or no core nucleus category showed a postoperative loss in discriminative performance.

Inspection of the data in Table 1 indicates that the turtles with the greatest amounts of core nucleus damage showed the greatest postoperative discriminative impairments. To assess this tendency statistically, a Kendall tau rank-order correlation coefficient was calculated (with corrections for ties). Turtles were ranked for their core nucleus damage in terms of the total bilateral damage indicated in Table 1, with the turtle with the greatest amount of core nucleus damage ranked first. Turtles' behavioral performance was ranked by savings score, with the turtle showing the greatest loss being ranked first. Turtles that did not relearn were considered tied in ranking and were ranked ahead of turtles that did relearn. The resultant Kendall tau was $.642(\mathrm{n}=8)$, which is significant at the .05 level (in a one-tailed test).

On the pattern problem also, turtles categorized as having sustained severe bilateral core nucleus destruction were severely impaired (Fig. 10). Two of these turtles showed large postoperative losses, while the third never relearned (see Table 2). Turtles with moderate and slight bilateral core nucleus damage showed postoperative losses, but not as great as those shown by the severe bilateral core nucleus turtles. Turtle 36 of the severe unilateral core nucleus category showed $88 \%$ postoperative savings. Turtle 66 of the severe unilateral core nucleus category also showed good postoperative discriminative performance, although turtle 66 did not achieve postoperative criterion (Fig. 10C). A Kendall tau rank-order correlation coefficient was calculated for the turtles trained on the pattern problem. The resulting Kendall tau was .509, which is significant at the .05 level (in a one-tailed test). 

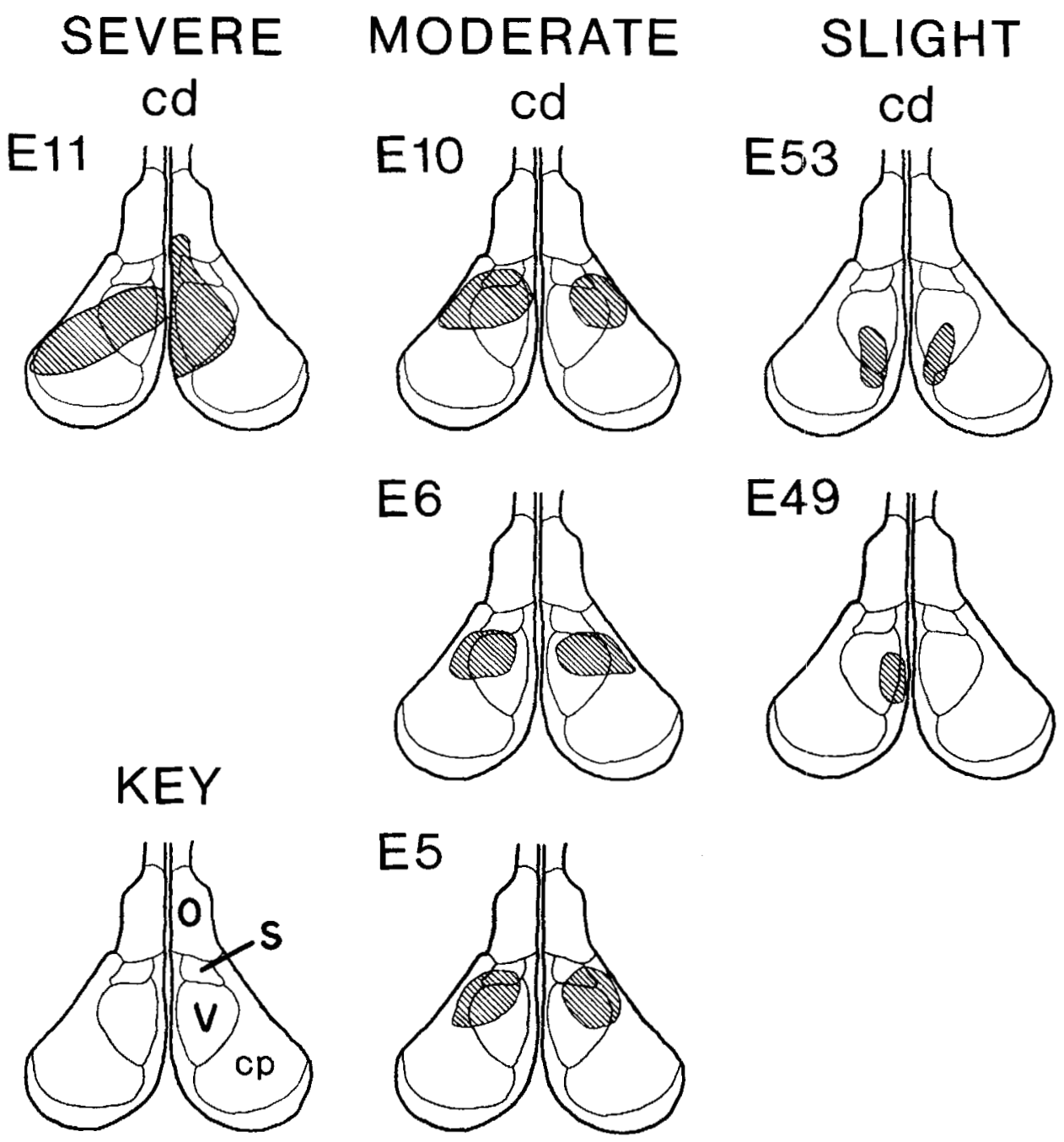

Fig. 7. Lesion reconstructions (as viewed from the dorsal aspect, with rostral toward the top) for turtles in the dorsal cortex lesion categories that had been trained on the pattern problem. Abbreviations the same as in Figure 5.

As noted above, structures adjacent to the core nucleus were damaged to varying extents in the course of making the lesions of the core nucleus. Further, turtles with greater amounts of core nucleus destruction tended, at least in the case of the intensity discrimination turtles, to have larger lesions overall. Therefore, we examined the correlation between the behavioral impairment and the total amount of tissue destroyed. Further, we examined the correlation between the behavioral impairment and the amount of damage to various structures other than the core nucleus. Because of the tendency of core nucleus damage to correlate with damage to other brain structures (as well as with overall lesion size), partial correlation statistics were used to separate out the contribution of core nucleus damage to the correlation of the behavioral impairment with damage to these other structures. Table 5 shows the correlation between the behavioral impairment and (1) the total amount of brain tissue destroyed, (2) the amount of paleostriatal complex (PC; including the paleo- striatum augmentum and the globus pallidus between A5.0 and A3.0) destroyed, (3) the amount of damage to the visual dorsal cortex, (4) the amount of damage to the pallial thickening, and (5) the amount of damage to portions of the anterior dorsal ventricular ridge lying outside the rotundorecipient zone. For each of these correlations, Kendall's partial correlation coefficient technique was used and the amount of damage to the core nucleus was held constant in each correlation. As can be seen, for the intensity discrimination turtles, only core nucleus damage appears to correlate with the behavioral impairment. All other correlations are .140 or less. In the pattern discrimination turtles, core nucleus damage also seems well correlated with the behavioral impairment. Damage to other structures, except the paleostriatum, does not appear to be correlated with the impairment on the pattern problem. Thus, the behavioral impairments on the intensity and pattern problems are not related to the overall amount of tissue damage. Further, the decrement in performance on these two problems is not 


\section{KEY}

\section{SEVERE $\mathrm{Cd}$}
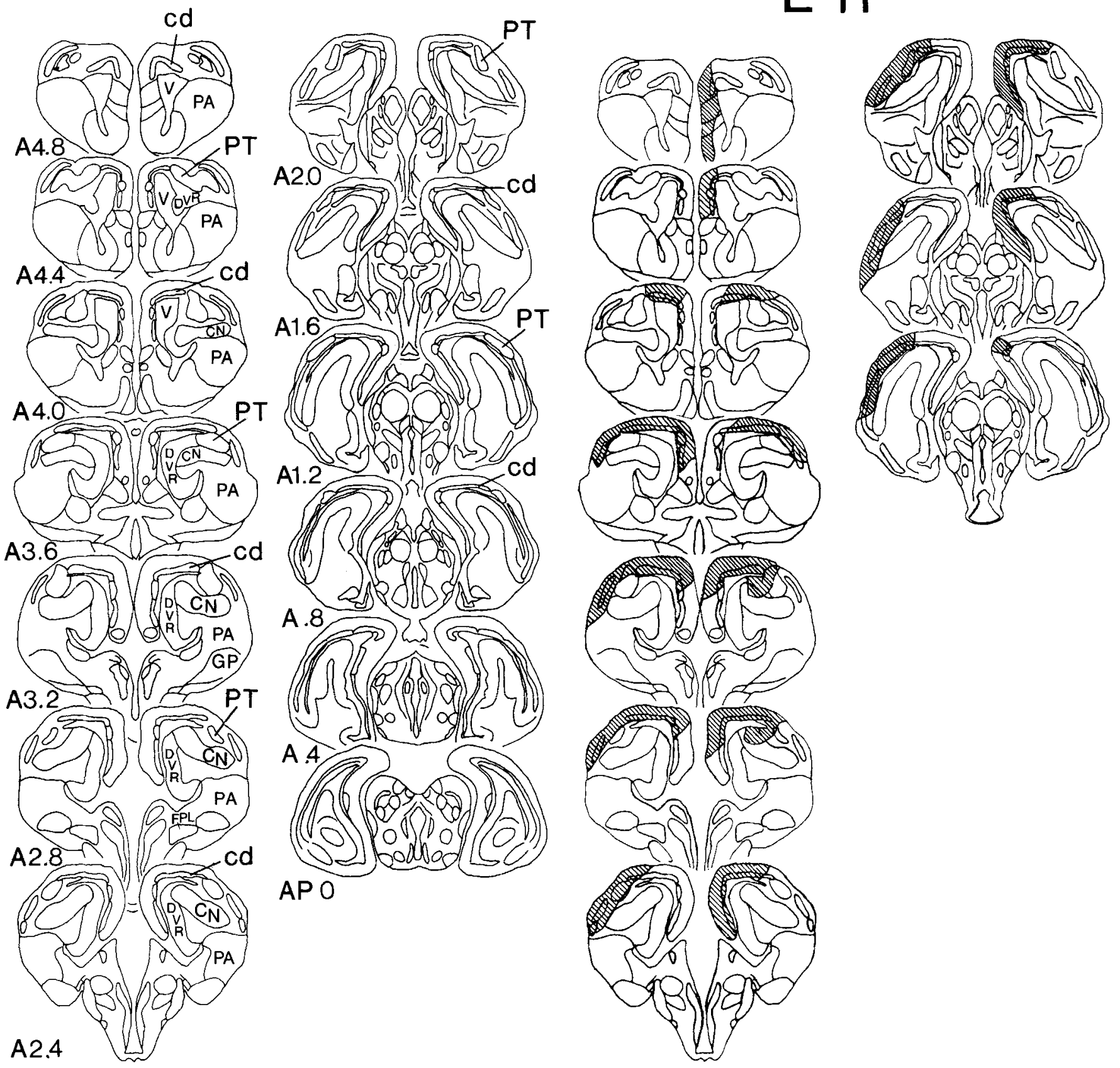

E 11 


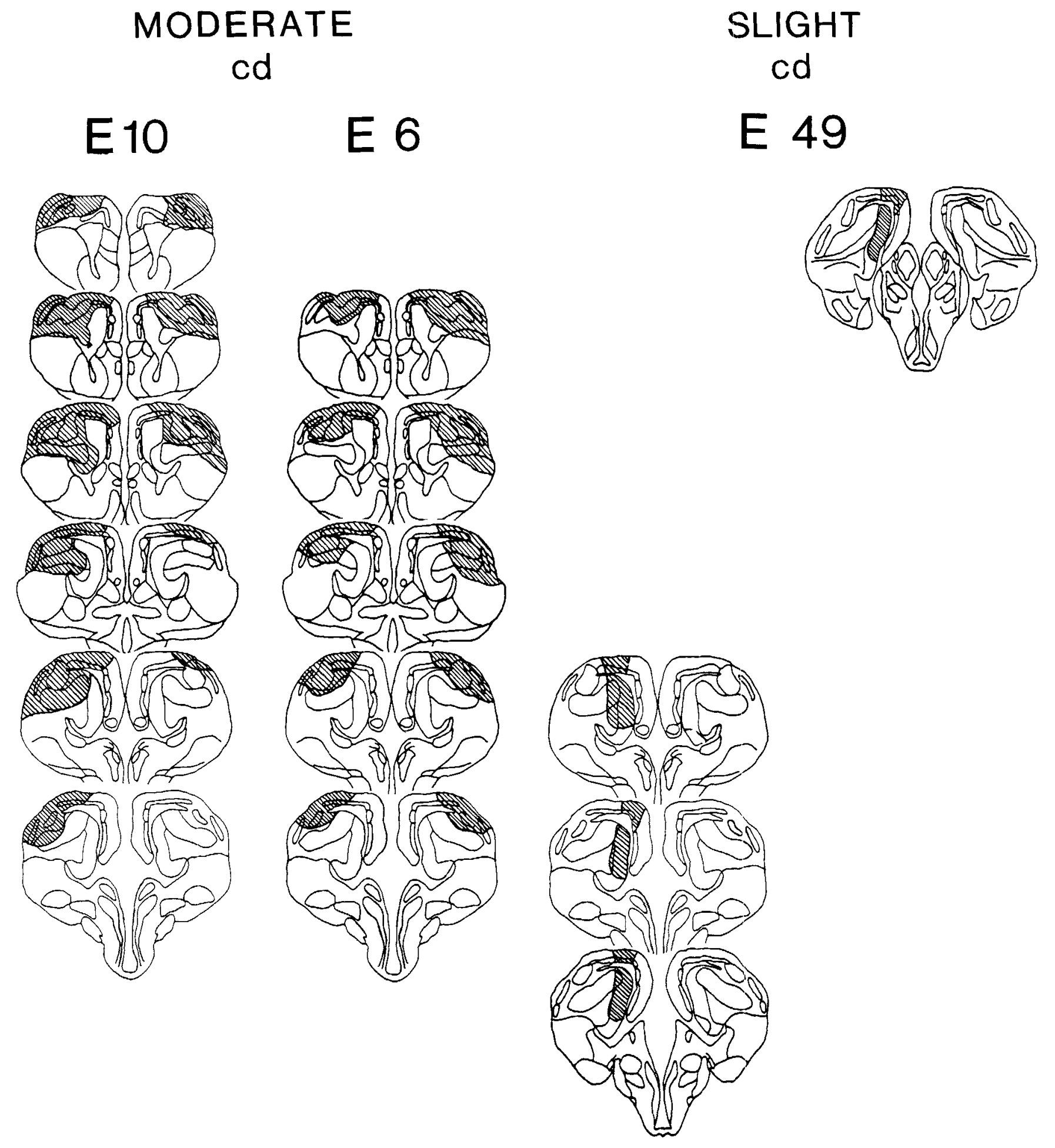



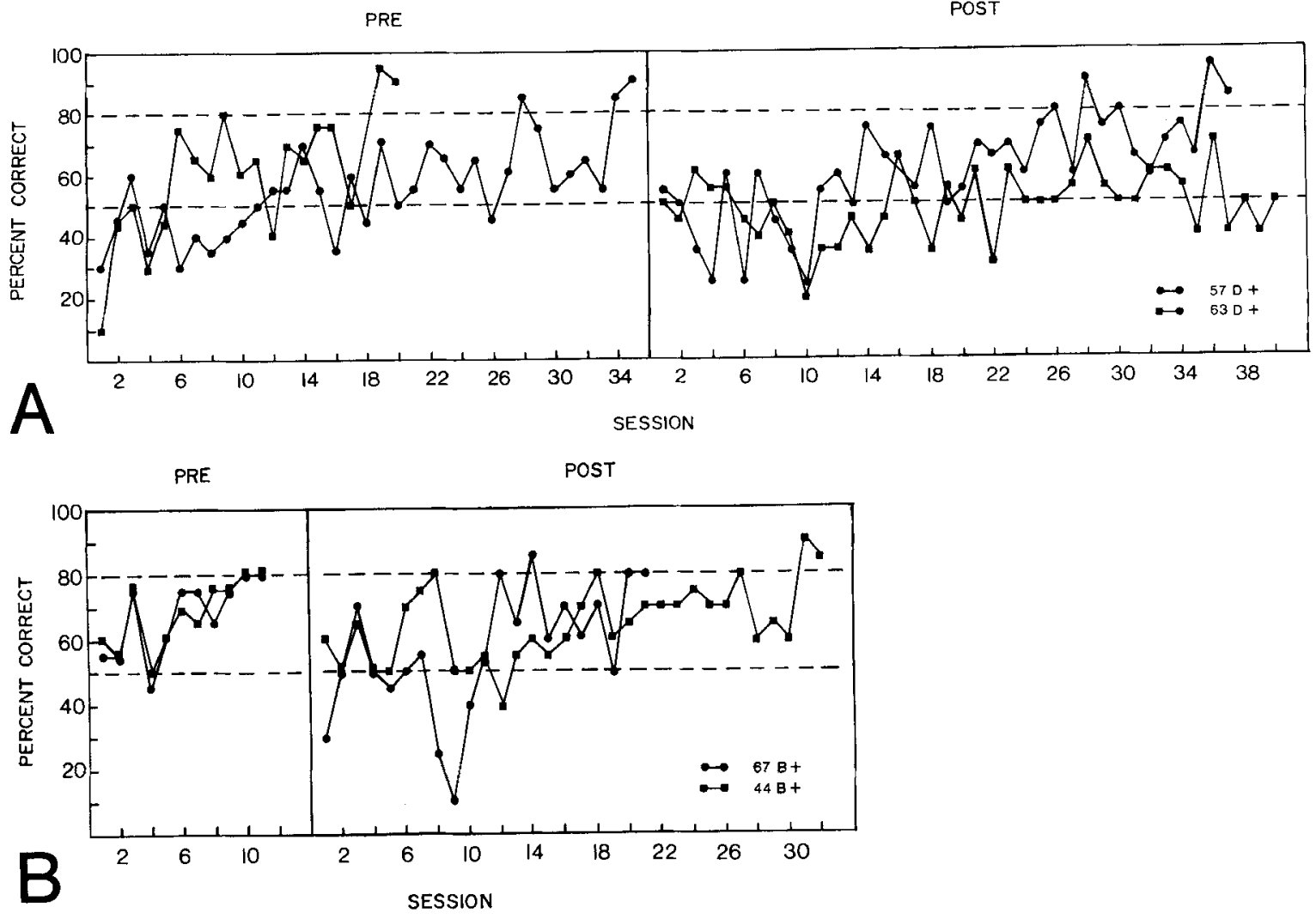

PRE POST
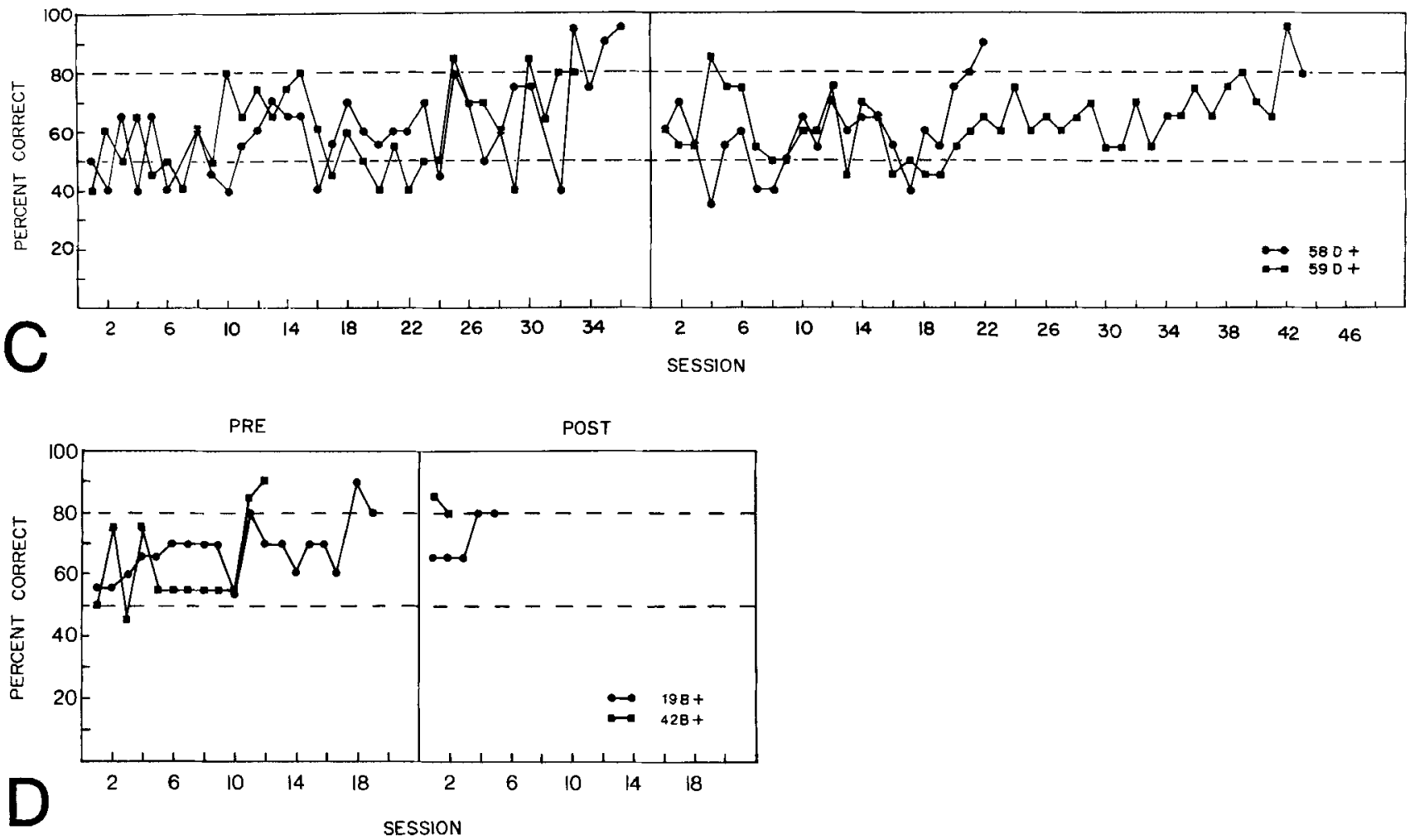

Fig. 9. Individual preoperative and postoperative learning curves for the core nucleus lesion turtles trained on the visual intensity problem. A,B. Severe $\mathrm{CN}$ lesions. C. Moderate CN lesions. $\mathrm{D}$. Slight or no $\mathrm{CN}$ lesions. $\mathrm{B}+$ and $\mathrm{D}+$ refer to the positive discriminative stimulus, bright or dim, respectively. 

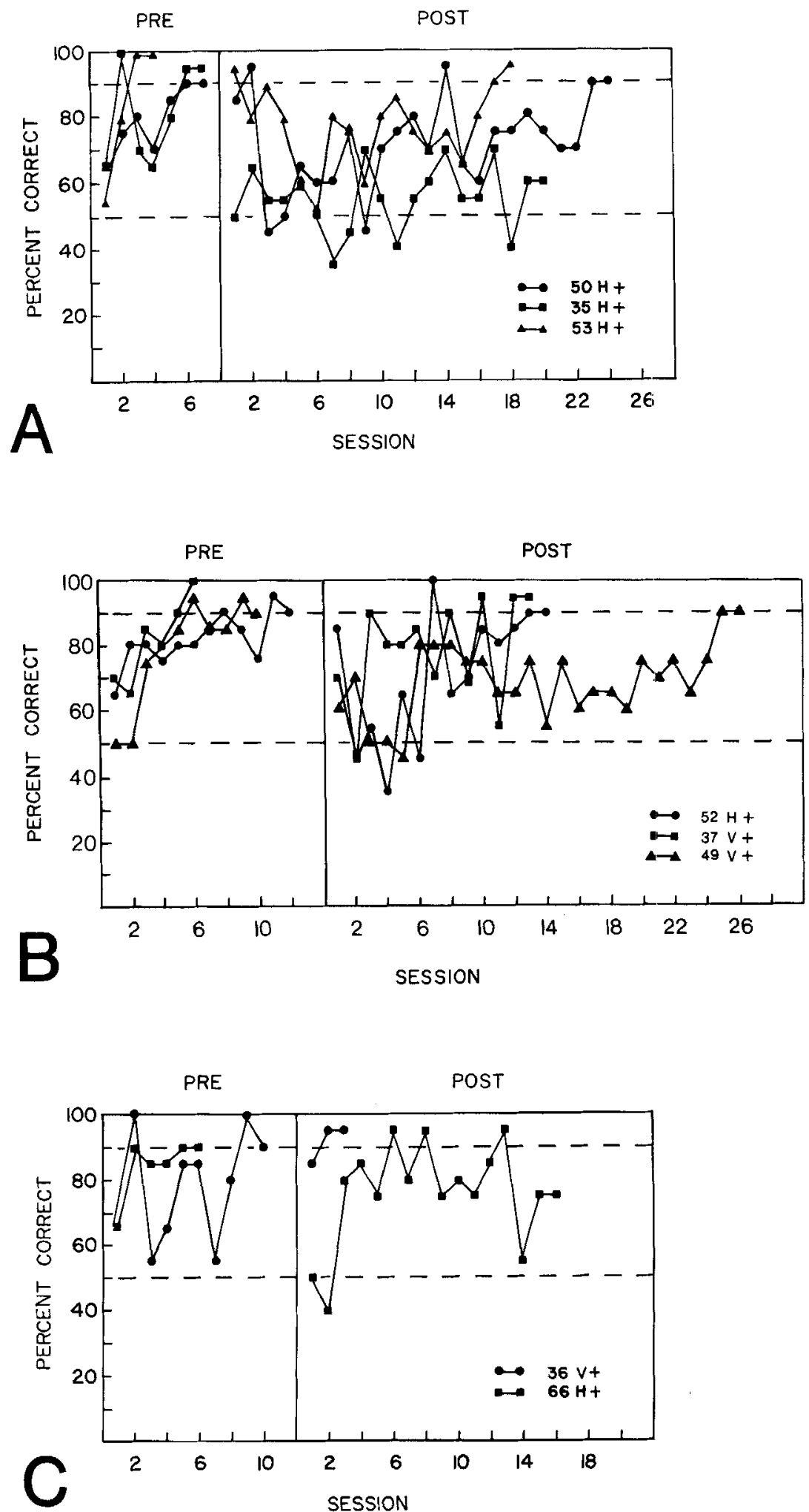

Fig. 10. Individual preoper ative and postoperative learning curves for the core nucleus lesion turtles trained on the pattern problem. A. Severe bilateral CN lesions. B. Moderate and slight CN lesions. C. Severe unilateral $\mathrm{CN}$ lesions. $\mathrm{V}+$ and $\mathrm{H}+$ refer to the positive stimulus, vertical or horizontal, respectively. 
TABLE 5. Kendall Taus for the Correlation of the Behavioral Impairment With the Amount of Damage to Various Telencephalic Structures for Each Group of Turtles ${ }^{1}$

\begin{tabular}{|c|c|c|c|c|c|c|}
\hline & $\mathrm{CN}$ & $\mathrm{TM}_{\mathrm{p}}{ }^{2}$ & $\mathrm{PC}_{\mathrm{p}}$ & $\mathrm{cd}_{\mathrm{p}}$ & $\mathrm{PT}_{\mathrm{p}}$ & $\mathrm{DVR}_{\mathrm{p}}$ \\
\hline Core nucleus turtles -intensity discrimination & 0.642 & 0.078 & -0.286 & 0.098 & 0.078 & 0.140 \\
\hline \multirow{2}{*}{ Core nucleus turtles - pattern discrimination } & 0.509 & -0.373 & 0.514 & 0.245 & 0.050 & -0.406 \\
\hline & $\mathrm{CN}$ & TM & cd & $\mathrm{PT}$ & $\mathrm{PT}_{\mathrm{p}}$ & \\
\hline Dorsal cortex turtles -intensity discrimination & 0.066 & -0.238 & -0.238 & -0.333 & -0.462 & \\
\hline Dorsal cortex turtles - pattern discrimination & 0.415 & 0.000 & 0.150 & 0.457 & 0.328 & \\
\hline
\end{tabular}

'The correlation between $\mathrm{CN}$ damage and the impairment is significant (at the 0.05 level in a one-tailed test) for both groups of $\mathrm{CN}$ lesion turtles. The correlation between PC damage and the impairment is high for the CN lesion turtles trained on the pattern problem. Significance tables are not available for the Kendall partial correlation coefficient, and thus, the significance level of the PC-behavioral impairment correlation cannot be assessed. Abbreviations as in list preceding Figure 1.

${ }^{2}$ The subscript p denotes a partial correlation coefficient with the contribution of the correlation between $\mathrm{CN}$ and the behavioral im. pairment to the given correlation held constant.

related to damage to either the dorsal cortex or the pallial thickening or the nonrotundorecipient portion of the anterior dorsal ventricular ridge. Performance on the pattern problem but not the intensity problem does appear to show a high correlation with the amount of damage to the paleostriatum. Although performance on the pattern problem correlated with the amount of damage to the paleostriatum, such damage was not necessary for the occurrence of the impairment. Both turtles 53 and 49, for example, had little paleostriatal damage but did show a substantial postoperative loss.

Dorsal cortex lesion turtles. Turtles in the dorsal cortex lesion categories required little or no remedial postoperative key training prior to the initiation of postoperative discriminative training. All turtles in the dorsal cortex lesion categories relearned their discriminative tasks to criterion. Savings scores were calculated for all turtles as in the case of the core nucleus turtles. These savings scores are presented in Tables 3 and 4 . The preoperative and postoperative learning curves for the turtles trained on the intensity problem and the pattern problem are presented in Figures 11 and 12, respectively. On both the intensity and pattern problems, postoperative performance by turtles with severe and moderate dorsal cortex damage was indistinguishable from that of turtles with sham lesions or slight dorsal cortex destruction. Although turtle E72 (moderate dorsal cortex - intensity group) and turtle E6 (moderate dorsal cortex - pattern group) did show postoperative losses, these two turtles were the only turtles among the dorsal cortex lesion turtles to show postoperative losses. Several other turtles, however, had similar or greater amounts of damage to the visual dorsal cortex and showed substantial postoperative savings. Thus, the postoperative performance of turtles E72 and E6 may be attributable to individual variation rather than to dorsal cortex damage per se. Since turtle E6 did sustain moderate bilateral core nucleus damage (which, as seen in the case of the core nucleus lesion turtles, affects pattern discrimination), the observed postoperative loss in turtle E6 may be attributable to damage to the core nucleus.

Kendall tau rank-order correlation coefficients were calculated for both the intensity and pattern discrimination turtles in order to assess the relationship between the amount of dorsal cortex damage and the postoperative behavioral performance. Although dorsal cortex damage did not result in obvious postoperative losses in discriminative ability, it still seemed possible that performance was correlated with the amount of dorsal cortex damage. Coef- ficients for the correlation with postoperative behavioral performance were also calculated for the amount of total tissue damaged, the amount of pallial thickening damaged, and the amount of core nucleus damaged. Performance and tissue damage were ranked as described above. None of the correlation coefficients are significant (at the .05 level in a one-tailed test). High correlations are seen, however, between core nucleus damage and the behavioral impairment and between pallial thickening damage and the behavioral impairment in the pattern discrimination turtles (see Table 5). Holding the amount of core nucleus damage constant, the partial correlation coefficient between pallial thickening damage and the impairment was less than the correlation between $\mathrm{CN}$ damage and the impairment.

\section{DISCUSSION}

Previous anatomical studies in turtles have established the existence of two separate visual channels, the tectothalamofugal and the retinothalamofugal, that project to the telencephalon, terminating in the core nucleus and the dorsal cortex, respectively (Hall and Ebner, '70a,b; Foster and Hall, '75; Hall et al., '77; Belekhova, '79; Balaban and Ulinski, '81a,b). Both pathways seem to be lemniscal channels that convey visual input to the telencephalon (Hall et al., '77; Belekhova, '79; Balaban and Ulinski, '81a,b). The present study has used the lesion technique to examine the role of these telencephalic visual structures in the visual discriminative performance of the turtle. Large bilateral lesions of the core nucleus were found to impair turtles in their performance of both a pattern discrimination problem and a visual intensity discrimination problem. Dorsal cortex lesions, on the other hand, were found to have no discernible effect on the performance of the visual discriminative tasks used in the present study. Although the anatomical data indicate that both the core nucleus and the dorsal cortex are involved in visual functions, the present results suggest that the core nucleus plays a greater role in visual discriminative tasks such as employed in the present study. In pigeons also, the telencephalic terminus of the tectothalamofugal pathway (the ectostriatum) plays a greater role in visual discriminative performance than does the telencephalic terminus of the retinothalamofugal pathway (the visual Wulst; Hodos, '76).

\section{Specificity of lesions}

Although it proved difficult to limit the lesions exclusively to either the core nucleus or the dorsal cortex, the 


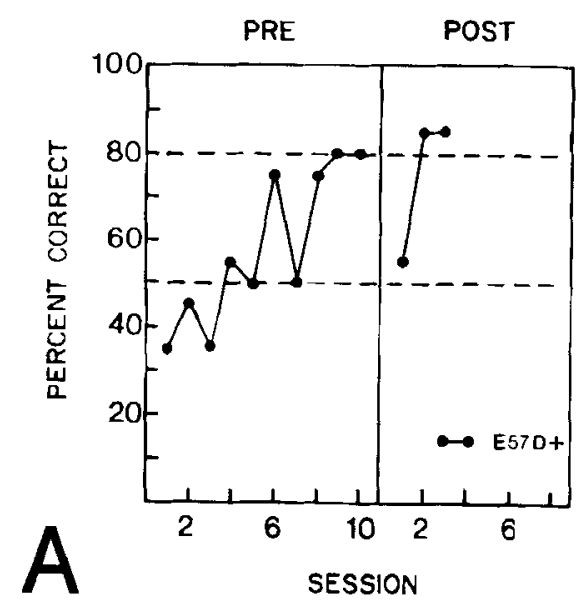

PRE

POST

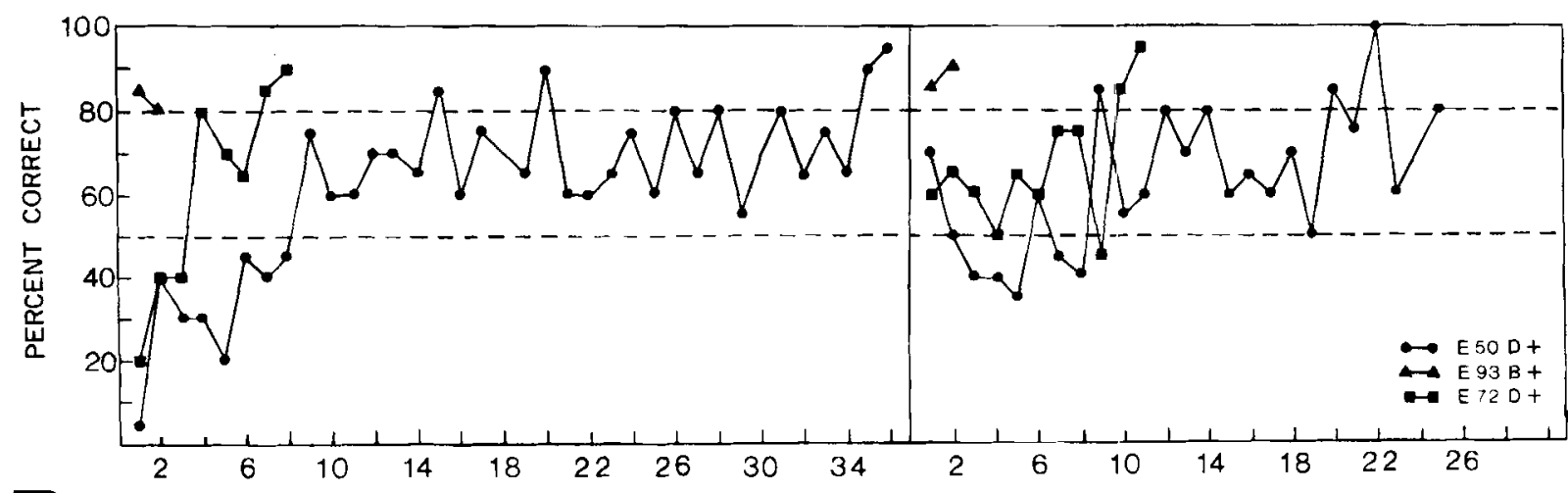

$\mathrm{B}$

SESSION

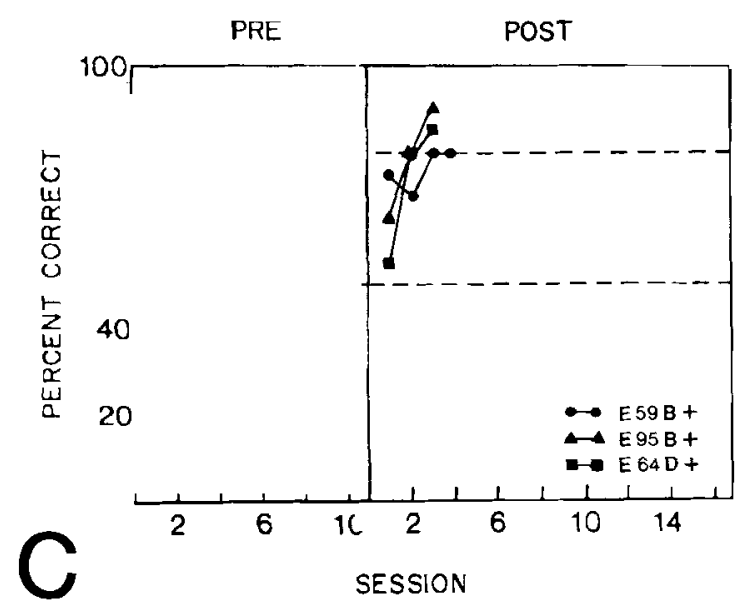

Fig. 11. Individual preoperative and postoperative learning curves for dorsal cortex lesion turtles trained on the visual intensity problem. A. Severe dorsal cortex lesions. B. Moderate dorsal cortex lesions. C. Slight or negligible dorsal cortex lesions and sham lesions. 

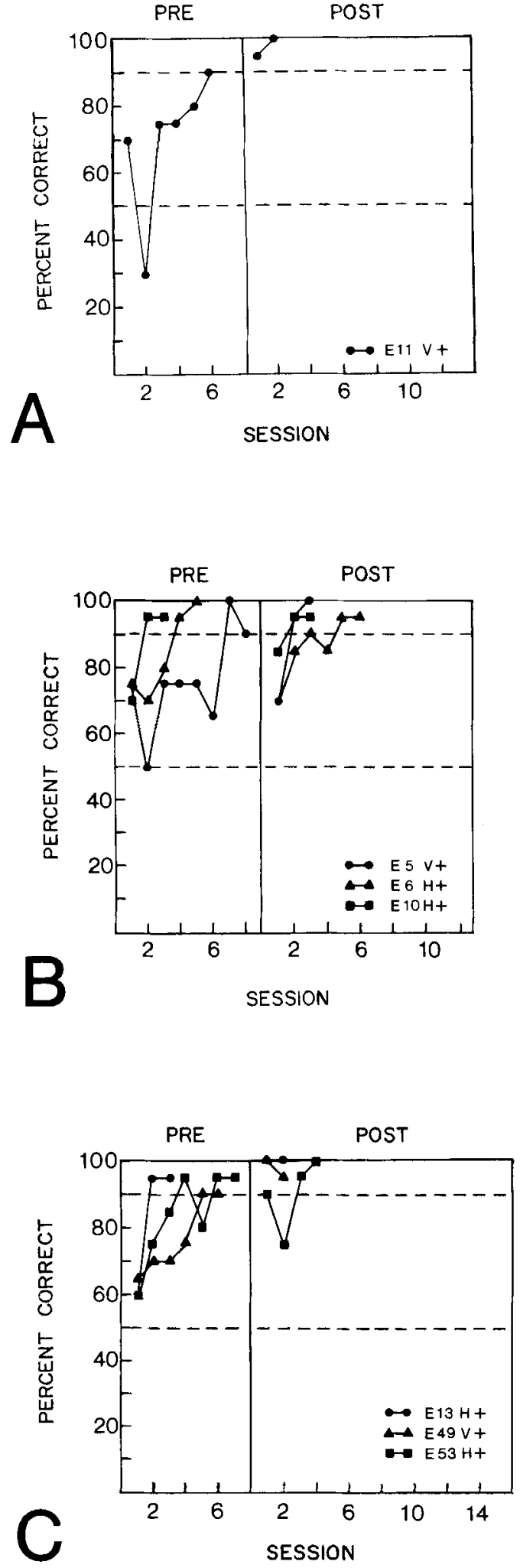

Fig. 12. Individual preoperative and postoperative learning curves for dorsal cortex lesion turtles trained on the pattern problem. A. Severe dorsal cortex lesions. B. Moderate dorsal cortex lesions. C. Slight or negljgible dorsal cortex lesions and sham lesions. values for the Kendall partial correlation coefficients (that express the relationship between the behavioral impairment and the damage to various structures other than the core nucleus and dorsal cortex) suggest that (1) the observed impairments in the core nucleus group were specifically correlated with amount of core nucleus damage and (2) any observed impairments in the dorsal cortex lesion group were not correlated with the amount of damage to the dorsal cortex. In the core nucleus lesion turtles the behavioral impairment did not correlate with the amount of total tissue destroyed (when the amount of core nucleus damage was held constant by statistical means). Comparison of individual turtles also demonstrates this point (see turtles 35 and 36 in Table 2). Similarly, the impairments in the dorsal cortex-lesioned group of turtles did not correlate with the amount of total telencephalic tissue damaged. Across both the core nucleus and dorsal cortex lesion groups, the behavioral impairments showed a consistent correlation with core nucleus damage. Even in the dorsal cortex turtles trained on the pattern problem, the impairments that were observed appeared to be correlated with the amount of core nucleus damage. Damage to other structures such as the pallial thickening or nonrotundorecipient portions of the anterior dorsal ventricular ridge was not correlated with impairments in discriminative performance (when the amount of damage to the core nucleus was held constant). It is interesting to note that damage specifically to the rotundorecipient portion of the dorsal ventricular ridge (i.e., the core nucleus) is correlated with the behavioral impairment. This correlation is also evident in a comparison of individual turtles. Turtles 36 and 50 of the pattern discrimination group sustained similar amounts of damage to the nonrotundorecipient portion of the anterior dorsal ventricular ridge. These two turtles differed, however, in that turtle 50 sustained severe bilateral damage to the core nucleus while turtle 36 sustained only severe unilateral damage to the core nucleus. Turtle 50 showed a considerable postoperative loss, while turtle 36 showed $88 \%$ savings.

For the pattern discrimination turtles, damage to the paleostriatum did correlate with the behavioral impairment, even when a correction was made (Kendall's partial correlation coefficient) for the contribution of the core nucleus-paleostriatum correlation to the correlation of paleostriatal damage with the behavioral impairment. In a previous study we found that extensive bilateral damage to the basolateral portion of the turtle telencephalon, i.e., the paleostriatal region, resulted in severe discriminative impairments (Reiner and Powers, ' 80 ). We interpreted these results as reflecting the destruction of the visual thalamofugal fibers as they course through the basolateral telencephalon. The basis of the correlation of paleostriatal damage with the impairment on the pattern problem in the present study is unclear. No such correlation is evident in the case of the intensity discrimination turtles. The fibers of the rotundo-core nucleus projection do course through the portions of the paleostriatum that were lesioned in these turtles. Thus, the correlation between paleostriatal damage and the behavioral impairments may reflect that the lesions destroyed rotundal afferent axons en route to the core nucleus. In such cases, the amount of direct core nucleus damage may not give a good reflection of the amount of loss of input to the core nucleus. The behavioral impairment would then tend to show a correlation with paleostriatal damage even when corrected for the correlation 
of paleostriatal damage with core nucleus damage. An alternate possibility is that the paleostriatum is to some extent involved in pattern discrimination. An input of nucleus rotundus to the paleostriatum has been claimed by some authors (Kruger and Berkowitz, '60; Hall and Ebner, '70b). The horseradish peroxidase data strongly indicate, however, that nucleus rotundus does not project to the paleostriatum (Parent, '76; unpublished observations). Thalamic nuclei situated dorsal and lateral to nucleus rotundus (i.e., nuclei dorsomedialis anterior and dorsolateralis anterior) have been found to project to the paleostriatum (Balaban and Ulinski, '81a). The reptilian paleostriatal complex has been reported to give rise to a major bisynaptic input (via the pretectal structure termed the dorsal nucleus of the posterior commissure) to the tectum (Reiner et al., '80). Damage to the paleostriatum may influence pattern discrimination by affecting such pathways. Bilateral destruction of the avian homologue of the dorsal nucleus of the posterior commissure, however, does not affect pattern discrimination (Bugbee, '79). Although the basis of the correlation between paleostriatal damage and the behavioral impairment is presently unclear, it is evident that paleostriatal damage is not necessary in order to observe impairments in either the pattern problem (see turtles 53 and 37 in Table 2) or the intensity problem.

Although dorsal cortex damage itself did not result in any behavioral impairments in the present study, the possibility exists that dorsal cortex damage plus core nucleus damage results in greater impairments than does core nucleus damage alone. In birds, combined damage to the tectothalamofugal and retinothalamofugal systems results in greater impairments than does damage to the tectothalamofugal system alone (Hodos, '76). In the present study, turtles with core nucleus lesions sustained varying amounts of damage to the dorsal cortex. Several turtles sustained extensive bilateral core nucleus damage with only slight dorsal cortex damage (see Tables 1,2 ). In these turtles, the possibility that the lesions destroyed the geniculocortical fibers en route to the dorsal cortex was negligible since the lesions did not extent as far lateral as the lateral edge of the core nucleus and pallial thickening (where the geniculocortical fibers course), except at very rostral levels of the visual portion of the dorsal cortex. These turtles showed substantial impairments in visual discriminative performance. The discriminative impairments in these turtles were not observably different than those in turtles that had equal damage to the core nucleus but greater amounts of dorsal cortex damage (e.g., compare turtles 59 and 67 in Table 1). Similarly, pallial thickening damage (which itself did not correlate with the discriminative impairments in any of the groups of turtles) did not appear to increase obviously the severity of the deficit seen with $\mathrm{CN}$ lesions. Although dorsal cortex or pallial thickening lesions may synergize with core nucleus lesions to produce greater impairments than any of these lesions alone, such a possibility is not obviously supported by the data in the present study.

\section{Functions of core nucleus and dorsal cortex}

The present results show that core nucleus damage does impair turtles in their ability to perform visual discriminations. Physiological and anatomical data indicate that while the core nucleus and nucleus rotundus show some measure of responsivity to nonvisual stimuli, the major afferent fibers that project to both nucleus rotundus and the core nucleus convey visual information (Belekhova and Kosareva, '71; Balaban and Ulinski, '81b). Thus, it seems likely that the impairment that follows damage to the core nucleus does represent an impairment in visual functions and does not reflect a nonspecific diminution in discriminatory ability. Consistent with the idea that the tectothalamofugal pathway is involved specifically in visual functions, we have found that lesions of nucleus rotundus result in elevations in visual intensity difference thresholds (Powers and Frank, '80, '83). Further, we have found that lesions of the core nucleus differentially affect pattern and color discrimination on a task involving shifts between problems along these two dimensions (Cranney and Powers, '81): Turtles with core nucleus lesions were capable of normal performance on the color problem, but performed more poorly than the controls when shifted to the pattern problem. Such impaired performance on one set of visual problems, but not on a second, suggests that the core nucleus does play a specific role in visual processing.

The specific visual functions affected by our core nucleus lesions are uncertain. In a previous study we found that extensive lesions of nucleus rotundus, the diencephalic component of the tectothalamofugal pathway, severely impair turtles in their ability to perform visual intensity and pattern discriminations (Reiner and Powers, '78). Similarly, in the present study, extensive lesions of the core nucleus, the telencephalic target of nucleus rotundus, impair turtles in visual intensity and pattern discrimination. Core nucleus lesions of a size too small to produce an impairment on the intensity problem did produce an impairment on the pattern problem (see turtle 42 in Table 1 and turtles 37 and 52 in Table 2). These results suggest that the core nucleus, as well as nucleus rotundus, may play some role in form vision. Such a conclusion is inconsistent with the proposal of others regarding the role of the ascending tectothalamofugal pathway in turtles (Rainey, '80; Balaban and Ulinski, '81b; Dunser et al., '81). Anatomical data indicate that at the level of both the tectal input to nucleus rotundus and the rotundal input to the core nucleus, the tectothalamofugal pathway is characterized by individual axons with widely branched terminations. Fur. ther, the tectal input to nucleus rotundus arises from a tectal layer (known as the stratum griseum centrale) whose cells possess dendrites that are widely branched in the superficial layers of the tectum (Reiner, unpublished observations). The physiological data indicate that units in the core nucleus do indeed possess wide visual receptive fields that frequently span nearly the entirety of the visual field of one eye (Belekhova, '79; Dunser et al., '81). Such results have led some to the suggestion that the ascending tectothalamofugal visual pathway in turtles cannot be involved in form vision since the anatomical configuration of this system seemingly precludes this possibility (Rainey, ' 80 ; Balaban and Ulinski ' $81 \mathrm{~b}$ ). These authors have suggested that the tectothalamofugal pathway in turtles mediates temporal aspects of visual processing, i.e., movement detection. Studies in birds, however, have recently shown that the presence of wide receptive fields and extensive terminal branching of individual axons do not preclude the possibility that a visual pathway is involved in form vision. The avian tectothalamofugal pathway also possesses units with wide receptive fields (Revzin, '70) and a seemingly nonretinotopic organization (Karten and Revzin, '66/67; Karten and Hodos, '70; Benowitz and Karten, '76; Hunt and Kunzle, '76). Nonetheless, lesions of nucleus ro- 
tundus and ectostriatum in pigeon both result in impairments in the performance of pattern discriminations (Hodos and Karten, '66, '70). Further, lesions of nucleus rotundus have recently been shown to result in permanent losses in acuity in pigeons (Macko and Hodos, '79). In contrast, lesions of components of the retinothalamofugal pathway do not impair birds in pattern discrimination or result in acuity losses (Hodos et al., '73; Macko and Hodos, 79). Thus, the anatomical data alone do not clarify the role of nucleus rotundus or its telencephalic target in visual functions. The behavioral data suggest that the tectothalamofugal system of birds and reptiles plays some role in form vision. Although units in the core nucleus of turtle do show wide receptive fields, such units are reported to be relatively finely tuned to parameters of the test stimulus (Belekhova, 79). Such results have led Belekhova ('79) to suggest that the core nucleus is involved in analyzing specific visual features. On the basis of observations similar to those above, Ulinski ('83) has recently suggested that the tectothalamofugal visual pathway of reptiles may mediate some aspects of spatial or form vision. The role of the dorsal cortex is unclear from the present study. The dorsal cortex does contain a crude retinotopic map (Orrego, '61; Belekhova, '79) and visual units of the dorsal cortex vary in size from a few degrees to the entire visual field of one eye (Belekhova, '79). Although the visual portion of the dorsal cortex appears to receive thalamic input from only the dorsal lateral geniculate nucleus, the visual portion of the dorsal cortex also receives input from the medial and dorsomedial cortices (Desan, '81; Reiner and Eldred, '82). Input from these other sources may account for the multimodal responsivity attributed to visually responsive units of the dorsal cortex (Belekhova, '79). The present results suggest that the role of the dorsal cortex in vision is too subtle to be detected by the techniques used in the present study. The dorsal cortex has been suggested to play a role in visual associative functions (Belekhova, '79). Cranney and Powers ('81) have recently shown that lesions of cortex in turtles result in impairments in the performance of reversals on a visual task.

\section{Comparison to other studies}

Previous studies in a variety of reptiles have not reported impairments in the performance of visual tasks following lesions of either dorsal cortex or core nucleus (or its equivalent). Hertzler and Hayes ('67) noted that dorsal cortex lesions have no effect on either optokinetic nystagmus or visual cliff choices in turtles. Fite et al. (79), however, have recently suggested that optokinetic nystagmus in turtles may be mediated by subtelencephalic visual centers - specifically, the accessory optic system (the nucleus of the basal optic root and its projection targets) and the nucleus lentiformis mesencephali (and its projection targets). Peterson ('80) has reported that lesions of the dorsal cortex in the lizard Dipsosaurus dorsalis do not affect visual intensity difference thresholds but do result in impairments in spatial reversal learning. Based on a presumed homology of the dorsal cortex to the avian Wulst, impair ments in intensity difference thresholds might be expected (Pasternak and Hodos, '77). Peterson concludes that the dorsal cortex of Dipsosaurus is not a visual structure comparable to the mammalian striate cortex but is more comparable to the hippocampus. The region termed the dorsal cortex in Dipsosaurus does not, however appear comparable to that termed the dorsal cortex in turtle. The region of the dorsal pallium examined in the Peterson study ('80) does not receive input from the retinothalamofugal pathway. The retinothalamofugal pathway in lizards appears to terminate in an extension of the cortex (similar to the pallial thickening of turtle) that has assumed a position below the ventricle within the dorsal ventricular ridge (Lohman and van Woerden-Verkley, '78; Bruce and Butler, '81). Some authors have assumed this region is not homologous to the dorsal cortex of turtles since the latter occupies a pallial position, but this conclusion does not appear to be a necessary one. In any case, it is clear that the Peterson ('80) study does not bear on the functions of the visual dorsal cortical area of turtles. Peterson's conclusion that a cortical region in reptiles is comparable to the mammalian hippocampus and plays a role in phenomena such as reversal learning, however, may be valid. Bass et al. ('73) have examined the role of the dorsal cortex and the dorsal ventricular ridge in visual discriminative behavior in the sidenecked turtle. They did not observe any impairments in visual discriminative performance following either lesions of the dorsal cortex or combined lesions of the dorsal cortex and dorsal ventricular ridge. Although their failure to find an effect of dorsal cortex lesions is consistent with the results of the present study, their failure to find an effect of dorsal ventricular ridge lesions is not. The difference between the present study and that of Bass et al. ('73) may be that the lesions of the dorsal ventricular ridge in the Bass et al. study ('73) did not destroy a large enough portion of the rotundorecipient portion of the dorsal ventricular ridge to produce an effect in their behavioral paradigm. Inspection of their lesion reconstructions indicates substantial sparing of the core nucleus region in even the turtles with the largest lesions. Another possible difference stems from the fact that the core nucleus in pleurodire turtles, such as side-necked turtles, is less well developed than that in cryptodire turtles, such as Chrysemys (R.G. Northcutt, personal commun.). Thus, core nucleus lesions in pleurodire turtles may have less of an effect on visual discriminative performance than in cryptodire turtles.

In a previous study (Reiner and Powers, ' 80 ), we noted that lesions of the basolateral telencephalon in turtles resulted in severe and lasting visual discriminative impairments. We suggested that these impairments might be based in the disruption of the ascending input to telencephalic visual areas in turtles. Our present observations on the effects of core nucleus lesions are consistent with this possibility. Basolateral telencephalic damage, however, results in more severe impairments than did combined core nucleus and dorsal cortex damage in the present study. The basis of this discrepancy is presently unclear. Perhaps basolateral telencephalic lesions result in a disruption of the input and output of a wide variety of telencephalic structures. Alternatively, the basolateral telencephalic lesions may produce a much more severe deafferentation of (and hence damage to) both the dorsal cortex and core nucleus than produced by any lesion in the present study. In the present study, no turtle sustained combined severe core nucleus damage and severe visual dorsal cortex damage. Several previous studies in lizards (Tarr, '77; Greenberg et al., '79) have noted that while lesions of the basolateral telencephalon result in a greatly decreased responsivity to visual social signals from conspecifics, lesions of the dorsal ventricular ridge produce no such effect. We suggested previously (Reiner and Powers, ' 80 ) that the alterations in species-specific behavior following telence- 
phalic lesions might in part be attributable to impairments in visual functioning following disruption of the fibers of the ascending visual pathways. The absence of an effect of dorsal ventricular ridge lesions is, however, puzzling. The histological reconstructions of Greenberg et al. ('79) suggest the possibility that the dorsal ventricular ridge lesions may have spared most of the rotundorecipient zone of the dorsal ventricular ridge (as defined in lizards by Hoogland, '77, and Lohman and van Woerden-Verkley, 78). In the present study, damage to the dorsal ventricular ridge, excluding the rotundorecipient portion of the core nucleus, did not correlate with the discriminative impairments. It would be of interest to know whether damage to the rotundorecipient portion of the lizard dorsal ventricular ridge does affect responses to visual social signals from conspecifics.

Ascending visual pathways to the telencephalon have been described in members of a variety of vertebrate classes, including not only the amniote classes, but also amphibians (Kicliter, '79) and cartilaginous fish (Ebbesson and Schroeder, '71; Cohen et al., '73; Schroeder and Ebbesson, '74; Luiten, ' $81 \mathrm{a}, \mathrm{b})$. A role of the telencephalic targets of these pathways in visual processing is well accepted for mammals and has recently become established for birds (Hodos, '76; Karten, '79). Recent studies in sharks have also demonstrated that telencephalic visual centers in cartilaginous fish play a role in visual discriminative functions (Graeber et al., '73, '78). Our previous studies (Reiner and Powers, '78, '80) in conjunction with our present study strongly indicate that the tectorecipient nucleus rotundus and its telencephalic target, the core nucleus, play a major role in visual processing in turtles.

\section{ACKNOWLEDGMENTS}

This paper is based in part on a dissertation submitted by the first author to the Graduate School of Arts and Sciences, Bryn Mawr College, in partial fulfillment of the requirements for the Ph.D. Degree. The research was supported by National Institutes of Mental Health grant 15902 to R.C. Gonzalez and by National Eye Institute grant 01657 to A.S. Powers. The support of Dr. Gonzalez throughout the course of this project is acknowledged with gratitude.

\section{LITERATURE CITED}

Balaban, C.D. (1978) Structure of the anterior dorsal ventricular ridge in turtles (Pseudemys scripta elegans). J. Morphol. 158:211-322.

Balaban, C.D., and P.S. Ulinski (1981a) Organization of thalamic afferents to anterior dorsal ventricular ridge in turtles. I. Projections of thalamic nuclei. J. Comp. Neurol. 200:95-129.

Balaban, C.D., and P.S. Ulinski (1981b) Organization of thalamic afferents to anterior dorsal ventricular ridge in turtles. II. Properties of the rotundo-dorsal nucleus map. J. Comp. Neurol. 200:131-150.

Bass, A.H., and R.G. Northcutt (1981) Retinal recipient nuclei in the painted turtle, Chrysemys picta: An autoradiographic and HRP study. J. Comp. Neurol. 199:97-112.

Bass, A.H., M.H. Pritz, and R.G. Northcutt (1973) Effects of telencephalic and tectal ablations on visual behavior in the side-necked turtle, Podocnemis unifilis. Brain Res. 55:455-460.

Belekhova, M.G. (1979) Neurophysiology of the forebrain. In A.C. Gans, R.G. Northcutt, and P.S. Ulinski (eds): Biology of the Reptilia. Neurology. London: Academic Press, pp. 287-359.

Belekhova, M.G., and A.A. Kosareva (1971) Organization of the turtle thalamus: Visual, somatic and tectal zones. Brain Behav. Evol. 4:337-375.

Benowitz, L.I., and H.J. Karten (1976) Organization of the tectofugal pathway in the pigeon: A retrograde transport study. J. Comp. Neurol. 167: $503-520$.
Bruce, L.L., and A.B. Butler (1981) Thalamocortical organization in two lizards. Soc. Neurosci. Abstr. 7:85.

Bugbee, N. (1979) The Effect of Bilateral Lesions in the Nucleus Spiriformis Lateralis on Visually Guided Behavior in the Pigeon. Ph.D. Thesis Univ, of Maryland, College Park, MD.

Cohen, D.H., S.A. Duff, and S.O.E. Ebbesson (1973) Electrophysiological identification of a visual area in shark telencephalon. Science 182:492494.

Cranney, J., and A.S. Powers (1981) Effects of telencephalic visual system lesions on reversal and dimensional shift in turtles (Chrysemys picta) Soc. Neurosci. Abstr. 7:176

Desan, P. (1981) Connections of cerebral cortex in the turtle (Pseudemys scripta elegans). Soc. Neurosci. Abstr. 7:85.

Diebschlag, V.E. (1938) Beobachtungen und Versuche an intakten und grosshirnlosen Eidechsen und Ringlnattern. Zool. Anz. 124:30-40.

Dunser, K.R.. J.H. Maxwell, and A.M. Granda (1981) Visual properties of cells in the anterior dorsal ventricular ridge of turtle. Neurosci. Lett. 25: 281-285.

Ebbesson, S.O.E., and D.M. Schroeder (1971) Connections of the nurse shark's telencephalon. Science 173:254-256.

Fite, K.V., A. Reiner, and S.P. Hunt (1979) Optokinetic nystagmus and the accessory optic system of pigeon and turtle. Brain Behav. Evol. 16:192202.

Foster, R.E., and W.C. Hall (1975) The connections and laminar organization of the optic tectum in a reptile (Iguana iguana). J. Comp. Neurol. 163:397-426.

Graeber, R.C., S.O.E. Ebbesson, and J.A. Jane (1973) Visual discrimination in sharks without optic tectum. Science 180:413-415.

Graeber, R.C., D.M. Schroeder, J.A. Jane, and S.O.E. Ebbesson (1978) Visual discrimination following partial telencephalic ablations in nurse sharks (Ginglymostoma cirratum). J. Comp. Neurol. 180:325-344.

Greenberg, N., P.D. MacLean, and J.L. Ferguson (1979) Role of the paleostriatum in species-typical display behavior of the lizard (Anolis carolinensis). Brain Res. 172:229-241.

Hall, W.C., and F.F. Ebner (1970a) Parallels in the visual afferent projections of the thalamus in the hedgehog (Paraechinas hypomelas) and the turtle (Pseudemys scripta). Brain Behav. Evol. 3:135-154.

Hall, W.C., and F.F. Ebner (1970b) Thalamotelencephalic projections in the turtle (Pseudemys scripta). J. Comp. Neurol. 140:101-122.

Hall, J.A., R.E. Foster, F.F. Ebner, and W.C. Hall (1977) Visual cortex in a reptile, the turtle (Pseudemys scripta) and (Chrysemys picta). Brain Res. 130:197-216.

Harting, J.K., W.C. Hall, and I.T. Diamond (1972) Evolution of the pulvinar. Brain Behav. Evol. 6:424-452.

Harting, J.K., I.T. Diamond, and W.C. Hall (1973) Anterograde degeneration study of the cortical projections of the lateral geniculate and pulvinar nuclei in the tree shrew (Tupaia glis). J. Comp. Neurol. 150:393440.

Hertzler, D.R., and W.N. Hayes (1967) Cortical and tectal function in visually guided behavior of turtles. J. Comp. Physiol. Psychol. 63:444-447.

Hodos, W., and H.J. Karten (1966) Brightness and pattern discrimination deficits in the pigeon after lesions of nucleus rotundus. Exp. Brain Res. 2:151-167.

Hodos, W., and H.J. Karten (1970) Visual intensity and pattern discrimination deficits after lesions of ectostriatum in pigeons. J. Comp. Neurol. 140:53-68.

Hodos, W., H.J. Karten, and J.C. Bonbright (1973) Visual intensity and pattern discrimination after lesions of the thalamofugal visual pathway in pigeons. J. Comp. Neurol. 148:447-468.

Hodos, W., and J.C. Bonbright (1974) Intensity difference thresholds in pigeons after lesions of the tectofugal and thalamofugal visual pathways J. Comp. Physiol. Psychol. 87:1013-1031.

Hodos, W., (1976) Vision and the visual system: A bird's eye view. In J.M. Sprague and A.M. Epstein (eds): Progress in Psychobiology and Physiological Psychology. New York: Academic Press, Vol. 6, pp. 29-62.

Hoogland, P.V. (1977) Efferent connections of the striatum in Tupinambis nigropunctatus. J. Morphol. 152:229-246.

Hughes, H.C. (1977) Anatomical and neurobehavioral investigations concerning the thalamo-cortical organization of the rat's visual system. J. Comp. Neurol. 175:311-336.

Hunt, S.P., and K.E. Webster (1972) Thalamo-hyperstriate interrelations in the pigeon. Brain Res. 44:647-651.

Hunt, S.P., and H. Kunzle (1976) Observations on the projections and intrinsic organization of the pigeon optic tectum: An autoradiographic 
study based on the anterograde and retrograde axonal and dendritic flow. J. Comp. Neurol. 170:153-172.

Johnston, J.P. (1915) The cell masses in the forebrain of the turtle, Cistudo carolina. J. Comp. Neurol. 25:393-468.

Karten, H.J., and A.M. Revzin (1966/1967) The afferent connections of the nucleus rotundus in the pigeon. Brain Res. 2:368-377.

Karten, H.J. (1969) The organization of the avian telencephalon and some speculations on the phylogeny of the amniote telencephalon. Ann N.Y. Acad. Sci. 167:164-179.

Karten, H.J., and W. Hodos (1970) Telencephalic projections of the nucleus rotundus in the pigeon (Columba livia). J. Comp. Neurol. 140:35-52.

Karten, H.J., W. Hodos, W.J.H. Nauta, and A.M. Revzin (1973) Neural connections of the "visual Wulst" of the avian telencephaion, Experimental studies in the pigeon (Columba livia) and owl (Speotyto cunicularia). J. Comp. Neurol. 150:253-278.

Karten, H.J. (1979) Visual lemniscal pathways in birds. In A.M. Granda and J.H. Maxwell (eds): Neural Mechanisms of Behavior in the Pigeon. New York: Plenum, pp. 409-430.

Kicliter, E. (1979) Some telencephalic connections in the frog, Rana pipiens. J. Comp. Neurol. 185:75-86.

Kruger, L., and E.C. Berkowitz (1960) The main afferent connections of the reptilian telencephalon as determined by degener ation and electrophysiological methods. J. Comp. Neurol. 115:125-142.

Lohman, A.H.M., and I. van Woerden-Verkley (1978) Ascending connections to the forebrain in tegu lizard. J. Comp. Neurol. 182:555-574.

Luiten, P.G.M. (1981a) Two visual pathways to the telencephalon in the nurse shark (Ginglymostoma cirratum). I. Retinal projections. J. Comp. Neurol. 196:531-538.

Luiten, P.G.M. (1981b) Two visual pathways to the telencephalon in the nurse shark (Ginglymostoma cirratum). II. Ascending thalamotelencephalic connections. J. Comp. Neurol. 196:539-548.

Macko, K.A., and W. Hodos (1979) Near-field visual acuity in pigeons fol lowing lesions of thalamic visual nuclei. Soc. Neurosci. Abstr. 5:144.

Nauta, W.J.H., and H.J. Karten (1970) A general profile of the vertebrate brain, with sidelights on the ancestry of the cerebral cortex. In F.O. Schmitt (ed): The Neurosciences: Second Study Program. New York: Rockefeller University Press, pp. 7-26.

Orrego, F. (1961) The reptilian forebrain. I. The olfactory pathways and cortical areas in the turtle. Arch. Ital. Biol, 99:425-445.

Parent, A. (1976) Striatal afferent connections in the turtle (Chrysemys picta) as revealed by retrograde axonal transport of horseradish peroxidase. Brain Res. 108:25-36.

Pasternak, T., and W. Hodos (1977) Intensity difference thresholds after lesions of the visual Wulst in pigeons. J. Comp. Physiol. Psychol. 91:485497.

Pert, A., and R.C. Gonzalez (1974) Behavior of the turtle (Chrysemys picta) in simultaneous, successive and behavioral contrast situations. J. Comp. Physiol. Psychol. 87:526-538.

Pettigrew, J.D., and Konishi, M. (1976) Neurons selective for orientation and binocular disparity in the visual wulst of the barn owl (Tyto alba).
Science 193:657-678.

Peterson, E. (1980) Behavioral studies of telencephalic function in reptiles. In S.O.E. Ebbesson (ed): Comparative Neurology of the Telencephalon. New York: Plenum Press, pp. 343-388.

Powers, A.S., and R. Frank (1980) Effects of nucleus rotundus lesions on visual intensity difference thresholds in turtles. Soc. Neurosci. Abstr. $6: 839$.

Powers, A.S., and R. Frank (1983) The effects of nucleus rotundus lesions on visual intensity difference thresholds in turtles. Brain Res. 264: $47-55$.

Powers, A.S., and A. Reiner (1980) A stereotaxic atlas of the forebrain and midbrain of the eastern painted turtle (Chrysemys picta picta). J. Hirnforseh. 21:125-159.

Pritz, M.B. (1975) Anatomical identification of a telencephalic visual are in crocodiles: Ascending connections of nucleus rotundus in Caiman crocodilus. J. Comp. Neurol. 164:323-338.

Rainey, W.T. (1980) Organization of Nucleus Rotundus, a Tectofugal Thalamic Nucleus in Pond Turtles. Ph.D. dissertation. Univ. of Chicago.

Reiner, A, and A.S. Powers (1978) Intensity and pattern discrimination in turtles following lesions of nucleus rotundus. J. Comp. Physiol. Psychol. 92:1156-1168.

Reiner, A., and A.S. Powers (1980) The effects of extensive forebrain lesions on visual discriminative performance in turtles (Chrysemys picta picta). Brain Res. 192:327-338.

Reiner, A., S.E. Brauth, C.A. Kitt, and H.J. Karten (1980) Basal ganglionic pathways to the tectum: Studies in reptiles. J. Comp. Neurol. 193 $565-589$.

Reiner, A., and W.D. Eldred (1982) Co-occurrence of substance P-like andcholecystokinin-8-like immunoreactivities in an intrinsic fiber system of the cortex in turtle. Soc. Neurosci. Abstr. 8:116.

Revzin, A.M., and H.J. Karten (1966/1967) Rostral projections of the optic tectum and the nucleus rotundus in the pigeon. Brain Res. 3:264-276.

Revzin, A.M. (1970) Some characteristics of widefield units in the brain of pigeon. Brain Behav. Evol. 3:195-204.

Schroeder, D.M., and S.O.E. Ebbesson (1974) Nonolfactory telencephalic afferents in the nurse shark (Ginglymostoma cirratum). Brain Behav. Evol. 9:121-155.

Snyder, M. (1973) The evolution of mammalian visual mechanisms. In $\mathrm{H}$ Autrum, R. Jung, W.R. Lowenstein, D.M. Mackay, and H.L. Teuber (eds): Handbook of Sensory Physiology, Vol. VII/3, Part A, pp. 693712 .

Sprague, J.M., J. Levy, A. Berardino, and G. Berlucchi (1977) Visual cortical areas mediating form discrimination in the cat. J. Comp. Neurol 172:441-488.

Tarr, R.S. (1977) Role of the amygdala in the intraspecies aggressive behavior of the iguanid lizard, Sceloporus occidentalis. Physiol. Behav. 18 $1153-115$.

Ulinski, P.S. (1983) Dorsal Ventricular Ridge: A Treatise on Forebrain Organization in Reptiles and Birds. New York: J. Wiley and Sons, Inc. (in press) 